\title{
Huanglianjiedu Decoction as an effective treatment for oral squamous cell carcinoma based on network pharmacology and experimental validation
}

Lejun Zhang ${ }^{1,2^{*}} \oplus$, Zhaoting Ling ${ }^{2}$, Zhengqiang Hu ${ }^{2,3}$, Guanmin Meng ${ }^{4,5}$, Xinqiang Zhu ${ }^{1}$ and Huifang Tang ${ }^{2^{*}}$

\begin{abstract}
Background: Oral squamous cell carcinoma (OSCC) is one of malignant tumors in oral and maxillofacial region with high fatality. Huanglianjiedu Decoction (HLJDD) is a well-known traditional Chinese medicinal prescription, which consists of Coptis chinensis Franch, Scutellaria baicalensis Georgi, Phellodendron amurense Rupr and Gardenia jasminoides J.Ellis. Some clinical studies showed HLJDD had good effectiveness on OSCC, but the mechanism is unclear.

Methods: In this study, potential components of HLJDD and putative targets were screened by Traditional Chinese Medicine Systems Pharmacology Database and Analysis Platform (TCMSP). Combining with potential targets of OSCC searched from Therapeutic Target Database (TTD) and Online Mendelian Inheritance in Man (OMIM), we drew protein-protein interaction (PPI) network by Cytoscape v3.2.0 software. After topological analysis we got core targets and further did Gene Ontology (GO) enrichment and Kyoto Encyclopedia of Genes and Genomes (KEGG) pathway analysis. Then we did the in vitro experiments to verify the major biological processes (cell cycle, apoptosis and proliferation) and signaling pathways (mitogen-activated protein kinase (MAPK), nuclear factor-kappa B (NF-kB), protein kinase B (AKT)) on OSCC cell lines, SCC-25 and CAL-27.
\end{abstract}

Results: The potential component targets number of Coptis chinensis Franch, Scutellaria baicalensis Georgi, Phellodendron amurense Rupr and Gardenia jasminoides J.Ellis were 39, 93, 81 and 88, respectively. Then we got 52 core targets which enriched in cell cycle, apoptosis, proliferation, MAPK activation etc. and obtained TOP30 pathways. On SCC-25 and CAL-27, HLJDD suppressed cell proliferation, induced late apoptosis and inhibited cell invasion and migration which were consistent with the results from network pharmacology analysis. Additionally, in cell cycle, we confirmed HLJDD inhibited G1 phase and arrested in S phase to reduce cell proliferation on SCC-25. In signaling pathways, HLJDD inhibited the phosphorylation of extracellular regulatory protein kinase 1/2 (ERK1/2) and NF-KB p65 (S468) on SCC-25 and CAL-27.

Conclusions: HLJDD played a potential therapeutic role on OSCC via inhibiting p-ERK1/2 and p-NF-KB p65 (S468).

Keywords: Network pharmacology, Huanglianjiedu Decoction, Oral squamous cell carcinoma

*Correspondence: 21718604@zju.edu.cn; tanghuifang@zju.edu.cn ${ }^{1}$ Central Laboratory, The Fourth Affiliated Hospital, Zhejiang University School of Medicine, Yiwu, Zhejiang, China

${ }^{2}$ Department of Pharmacology, School of Basic Medical Sciences, Zhejiang University, Hangzhou, Zhejiang, China

Full list of author information is available at the end of the article

\section{Background}

Oral squamous cell carcinoma (OSCC) is one of squamous cell carcinoma in the oral mucosal epithelium. Nearly 300,000 patients especially among young people worldwide have suffered OSCC and the prevalence is still

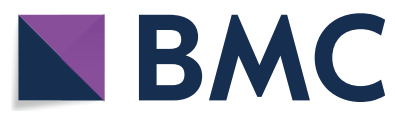

(c) The Author(s) 2021. Open Access This article is licensed under a Creative Commons Attribution 4.0 International License, which permits use, sharing, adaptation, distribution and reproduction in any medium or format, as long as you give appropriate credit to the original author(s) and the source, provide a link to the Creative Commons licence, and indicate if changes were made. The images or other third party material in this article are included in the article's Creative Commons licence, unless indicated otherwise in a credit line to the material. If material is not included in the article's Creative Commons licence and your intended use is not permitted by statutory regulation or exceeds the permitted use, you will need to obtain permission directly from the copyright holder. To view a copy of this licence, visit http://creativecommons.org/licenses/by/4.0/. The Creative Commons Public Domain Dedication waiver (http://creativeco mmons.org/publicdomain/zero/1.0/) applies to the data made available in this article, unless otherwise stated in a credit line to the data. 
increasing [1]. Many patients were found at the advanced stage, resulting in a high mortality rate of this disease [2]. Data showed 5-year survival rate of OSCC is only $50 \%[3,4]$, so finding the effective therapy for OSCC is urgent. Following the recognition of biomarkers, molecular-targeted therapy offered new approach for cancer therapy [5], including OSCC therapy. The key molecules and pathways for targeted therapy include growth factor receptors, Mitogen-activated protein kinase/Extracellular regulated protein kinases (MAPK/ERK) pathways, angiogenesis and epithelial-mesenchymal transition [6], which provide the possibility for individualized treatments.

Network pharmacology was firstly proposed and systematically described by Andrew L Hopkins in the Nature Biotechnology [7]. Based on nodes of the network to design multi-target drugs and synergistic effects of targeted drugs, network pharmacology is widely used to explore the effects or mechanisms of drugs on many diseases through an overall systemic perspective [8], such as respiratory diseases (acute lung injury, lung cancer etc.) $[9,10]$, kidney disease like pediatric adrenocortical carcinoma [11], liver disease like hepatocellular carcinoma [12] etc. Traditional Chinese Medicine (TCM) with a history of more than 5000 years, has a variety of herbal formulas. However, there are too many components to analyze the main mechanism of herbal formulas [13]. Many studies used network pharmacology to precisely analyze the targets of multiple drug components based on big databases, providing a novel analysis approach to screen the active ingredients and targets of TCM [8]. An new model called "multi-drug, multi-target" derived from network pharmacology, provides a new method to analyze and predict the targets and mechanisms of TCM [14].

Huanglianjiedu Decoction (HLJDD) is a classic ancient prescription of Qingrejiedu Decoction, which consists of Coptis chinensis Franch, Scutellaria baicalensis Georgi, Phellodendron amurense Rupr and Gardenia jasminoides J.Ellis [15]. The main effects of HLJDD are "Purging the fire and detoxifying". Previous researches suggested that HLJDD had therapeutic potentials on Alzheimer's disease [16], stroke [17], gastritis [18]. Growing evidences furtherly demonstrated that HLJDD had anti-infective [19], anti-inflammatory and anti-allergic effects [20], and so on. Moreover, HLJDD showed anti-tumor activities both in vivo and in vitro, it could significantly inhibit the growth of experimental tumor $\mathrm{H} 22$ in mice in a dose-dependent manner, and the drug serum had obvious inhibitory effects against human cancer cells, such as Swille, SPC-A-1, SGC-7901 and MCF-7 [21]. In clinical research, the effective rate of HLJDD for tongue cancer was nearly $83.3 \%$ [22]. All those evidences demonstrated that HLJDD was a very promising TCM prescription in cancer therapy. However, the mechanism of HLJDD on cancer is rarely. Wang et al. suggested that HLJDD inhibited eEF2 to block the progression of hepatocellular carcinoma on experimental animal model [23]. But the detailed mechanisms are still unclear. Based on the high cure rate of HLJDD on tongue cancer, we designed this study to explore the mechanisms of HLJDD on OSCC.

In this study, firstly we used network pharmacology to screen out the active ingredients and targets of HLJDD. Secondly, we performed protein-protein interaction (PPI) networks both the HLJDD active ingredients related and OSCC related targets to get the core targets, and through biological process and pathway enrichment analysis of core targets to reveal the inhibitory mechanism of HLJDD on OSCC. Finally, we selected some core signal pathways and performed experimental verification in vitro.

\section{Methods}

The whole workflow was illustrated in Graphical abstract. It shows the integrated workflow for elucidating the mechanism(s) of action of HLJDD in the treatment of OSCC. The workflow includes: 1 . Data collection: the collection of potential components of HLJDD and their putative targets, the collection of OSCC-related targets; 2. Enrichment analysis: the identification of core targets and their enriched pathways; 3 . Experimental validations of the important functions and pathways.

\section{Network pharmacology analysis Databases}

Traditional Chinese Medicine Systems Pharmacology Database and Analysis Platform (TCMSP) (http:// lsp.nwu.edu.cn/tcmsp.php) [24]; Therapeutic Target Database (TTD) (http://bidd.nus.edu.sg/BIDD-Datab ases/TTD/TTD.asp) [25]; Uniprot (https://www.unipr ot.org/) [26]; Online Mendelian Inheritance in Man (OMIM) (https://www.omim.org/) [27]; Search Tool for the Retrieval of Interacting Genes (STRING) (https:// string-db.org/) [28, 29]; DAVID (https://david.ncifcrf. gov/summary.jsp) [30].

\section{Software}

Cytoscape v3.2.0 software (an open source software for visualizing complex biomolecular interaction networks, integrating high-throughput data and connecting the network to functions such as a feature annotation database [31]); Bisogenet plug-in of Cytoscape (a new tool for gene network building, visualization and analysis [32]); CytoNCA plug-in of Cytoscape (for the central analysis and evaluation of protein interaction networks [33]); ClueGo plug-in of Cytoscape (a convenient tool to do 
the enrichment analysis including Gene Ontology (GO), pathway annotation analysis, etc. [34]).

\section{Prediction of target genes}

Based on the TCMSP database, the active ingredients and related targets of Coptis chinensis Franch, Scutellaria baicalensis Georgi, Phellodendron amurense Rupr and Gardenia jasminoides J.Ellis in HLJDD were obtained and then exported. According to oral bioavailability more than $30 \%$, we got potential active ingredients and targets of HLJDD. After screening, we transformed the protein names of targets to gene names by Uniprot Website (https://www.uniprot.org/). After preparing two files, we imported to Cytoscape v3.2.0 software and made HLJDD potential active ingredients-targets interaction network visualization. We searched OSCC related targets from Therapeutic Target Database (TTD) (http://bidd.nus.edu. sg/BIDD-Databases/TTD/TTD.asp) and Online Mendelian Inheritance in Man (OMIM) (https://www.omim. org/) database. After integrating these databases and deleting duplicates, we got final OSCC related targets. As showed above, protein names of OSCC related targets could be transformed to gene names (restricted to the Homo sapiens genus) by Uniprot Website (https://www. uniprot.org/) one by one.

\section{Protein-protein interaction (PPI) network construction}

HLJDD potential active ingredients related targets and OSCC related targets obtained in previous steps were imported into the Bisogenet plug-in of Cytoscape, so that five PPI network diagrams were obtained including Coptis chinensis Franch, Scutellaria baicalensis Georgi, Phellodendron amurense Rupr, Gardenia jasminoides J.Ellis potential active ingredients related targets and OSCC related targets, respectively. After merging these five PPI networks, we got an intersection network which called the HLJDD potential active ingredients related targets-OSCC related targets PPI network. Connecting with CytoNCA plug-in of Cytoscape, we evaluated the topological parameters and exported to a file. Then we selected the degree raw and calculated the median value. When imported twice the median value and the total number of nodes, the system automatically marked eligible nodes with yellow color which called core targets. The exported core targets could be used to build PPI network diagrams.

\section{Enrichment analysis of core targets}

ClueGO plug-in of Cytoscape was applied to analyze Gene Ontology (GO) and Kyoto Encyclopedia of Genes and Genomes (KEGG) for core targets, including Biological Process (BP), Cellular Component (CC) and Molecular Function (MF). Meanwhile, DAVID website (https:// david.ncifcrf.gov/summary.jsp) was also used for $\mathrm{GO}$ and KEGG analysis in this study.

\section{Cell culture and experiment \\ Preparation of Huanglianjiedu Decoction (HLJDD) and control drugs}

Coptis chinensis Franch (Batch No: 170901), Scutellaria baicalensis Georgi ((Batch No: 170801), and Gardenia jasminoides J.Ellis (Batch No: 170601) were provided by Anhui people's Traditional Chinese Medicine Pieces Co., Ltd., Phellodendron amurense Rupr (Batch No: 170506) was provided by Hangzhou East China Traditional Chinese Medicine Pieces Co., Ltd. The Four TCM pieces were procured from ZhangTongtai Pharmacy. After the four pieces were powdered, we mixed Coptis chinensis Franch, Scutellaria baicalensis Georgi, Phellodendron amurense Rupr and Gardenia jasminoides J.Ellis in the ratio of 3:5:5:5, the formulation was decocted twice by refluxing with $1800 \mathrm{~mL}$ water for $60 \mathrm{~min}$ and $900 \mathrm{~mL}$ water for $30 \mathrm{~min}$. Both the solutions were collected then concentrated by water-evaporation to $1 \mathrm{~g} / \mathrm{mL}$ and stored at $-20{ }^{\circ} \mathrm{C}$ [35]. Before administration, HLJDD solution was filtered with $0.22 \mu \mathrm{m}$ filter and diluted by cell culture medium to $5 \mathrm{mg} / \mathrm{mL}, 2.5 \mathrm{mg} / \mathrm{mL}$ and $1.25 \mathrm{mg} /$ mL HLJDD working concentrations respectively. Paclitaxel was purchased from Yangtze River Pharmaceutical (Jiangsu, China), the concentration of stock solution was $6 \mathrm{mg} / \mathrm{mL}$. It was diluted to $6 \mu \mathrm{g} / \mathrm{mL}$ with cell culture medium before administration. Cisplatin was purchased from Qilu Pharmaceutical (Jinan, China) and stock solution $(1 \mathrm{mg} / \mathrm{mL})$ prepared with phosphate buffer saline (PBS). It was diluted to $5 \mu \mathrm{g} / \mathrm{mL}$ with cell culture medium before administration.

\section{Cell culture}

The CAL-27 human tongue squamous carcinoma cell (CRL-2095) and SCC-25 human oral squamous carcinoma cell line (CL-0569) were purchased from ATCC (Rockville, MD, USA). The CAL-27 cells were cultured in DMEM-High Glucose medium and SCC-25 cells were cultured in MEM medium, both supplemented with 100 $\mathrm{U} / \mathrm{mL}$ penicillin, $100 \mu \mathrm{g} / \mathrm{mL}$ streptomycin and $10 \%$ fetal bovine serum (FBS) (Sigma-Aldrich, St. Louis, MO, USA) and incubated in $5 \% \mathrm{CO}_{2}$ at $37^{\circ} \mathrm{C}$. Cells were seeded in 6 -well plate or 96 -well plate at the density of $4 \times 10^{5}$ cells/ $\mathrm{mL}$. After $24 \mathrm{~h}$, cells were treated with HLJDD ( $5 \mathrm{mg} /$ $\mathrm{mL}, 2.5 \mathrm{mg} / \mathrm{mL}$ and $1.25 \mathrm{mg} / \mathrm{mL})$, paclitaxel $(6 \mu \mathrm{g} / \mathrm{mL})$ and cisplatin $(5 \mu \mathrm{g} / \mathrm{mL})$, respectively. At the same time, without drug administration cells were used as the control group. After administration for 24, 48 and $72 \mathrm{~h}$, cells in 96-well plate were harvested for Study Using sulforhodamine B (SRB) experiment. In addition, cells in 6-well plate were harvested after administration for $24 \mathrm{~h}$ to do 
wound healing assay, western blot analysis, flow cytometry of cell cycle and apoptosis.

\section{Wound healing assay}

Cells were seeded into 6-well plates at the density of $4 \times 10^{5}$ cells $/ \mathrm{mL}$ and cultured for $24 \mathrm{~h}$ at $37{ }^{\circ} \mathrm{C}$. After reaching $90-100 \%$ confluence, the cells were scraped vertically using sterile $1000 \mu \mathrm{L}$-pipette tips and washed with PBS to remove cellular debris. The cells were treated with HLJDD $(5 \mathrm{mg} / \mathrm{mL}, 2.5 \mathrm{mg} / \mathrm{mL}$ and $1.25 \mathrm{mg} / \mathrm{mL})$, paclitaxel $(6 \mu \mathrm{g} / \mathrm{mL})$ and cisplatin $(5 \mu \mathrm{g} / \mathrm{mL})$ respectively and then incubated in fresh serum-free medium for $24 \mathrm{~h}$. Images were collected at 0 and $24 \mathrm{~h}$ under an inverted microscope (Olympus, Japan). The area measurement was analyzed quantitatively by Image J software (National Institute of Health, USA) [36].

\section{Western Blot Analysis}

Cells were seeded into 6-well plates at the density of $4 \times 10^{5}$ cells $/ \mathrm{mL}$ and cultured for $24 \mathrm{~h}$ at $37^{\circ} \mathrm{C}$. Then cells were treated with HLJDD $(5 \mathrm{mg} / \mathrm{mL}, 2.5 \mathrm{mg} / \mathrm{mL}$ and $1.25 \mathrm{mg} / \mathrm{mL})$, paclitaxel $(6 \mu \mathrm{g} / \mathrm{mL})$ and cisplatin $(5 \mu \mathrm{g} / \mathrm{mL})$ respectively. After $24 \mathrm{~h}$ incubation, cells in 6-well plate were harvested and the proteins of cells were extracted with RIPA buffer (containing protease inhibitor cocktail, phosphatase inhibitor and phenylmethanesulfonyl fluoride (PMSF) and centrifuged at $12,000 \times g$ at $4{ }^{\circ} \mathrm{C}$ for $15 \mathrm{~min}$. Protein concentrations were detected by Bio-Rad reagent (Bio-Rad Inc., Hercules, CA, USA). The $5 \times$ loading buffer (Beyotime, Shanghai, China) was added to proteins and boiled at $100{ }^{\circ} \mathrm{C}$ for $5 \mathrm{~min} .30 \mu \mathrm{g}$ of proteins were separated by electrophoresis on SDSPAGE gels $(30 \mathrm{~V}$ for $30 \mathrm{~min}, 70 \mathrm{~V}$ for $40 \mathrm{~min}$ and $130 \mathrm{~V}$ for $30 \mathrm{~min}$ ), then gels were transferred to the nitrocellulose (NC) membrane (300 mA for $90 \mathrm{~min})$. After transferring time, the membranes were blocked for $60 \mathrm{~min}$ with $5 \%$ bovine serum albumin (BSA) then incubated with the primary antibody (p-ERK1/2 (ab76165, 1:3000, Abcam, U.K.), ERK1/2 (ab79853, 1:1000, Abcam, U.K.),

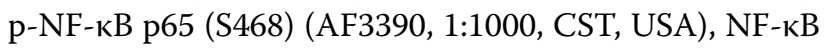
p65 (BS1253, 1:1000,Bioworld, USA), p-IKK $(\alpha+\beta)$ $(\mathrm{S} 180+\mathrm{S} 181)$ (ab55341, 1:1000, Abcam, U.K.), GAPDH (db106, 1:50000, Diagbio, China), p-AKT (\#4060, 1:1000, CST, USA), AKT1/2/3 (db1607, Diagbio, China), p-NF-кB p65 (S529) (BS4737, 1:1000, Bioworld, USA), p-NF-кB p65 (S276) (BS4135, 1:1000, Bioworld, USA), p-p38 (\#4511, 1:1000, CST, USA), p38 (db3666, 1:1000, Diagbio, China), p-JNK (\#9255, 1:1000, CST, USA) and JNK (\#9252, 1:1000, CST, USA)) at $4{ }^{\circ} \mathrm{C}$ overnight. After that, membranes were washed six times for 4 min each time with TBST and incubated with the secondary antibody (IRDye 800CW anti-rabbit (926-32211, 1:5000, LICOR Biosciences, USA) and IRDye 680RD anti-mouse
(926-68070, 1:5000, LI-COR Biosciences, USA) at room temperature for $90 \mathrm{~min}$. Lastly membranes were washed six times for 4 min each time with TBST and imaged with Odyssey CLx infrared imaging system (LI-COR Biosciences, USA). The bands were quantified by Imagine Studio Version 5.2 software (LI-COR Biosciences, USA) and total proteins or GAPDH were used to normalize the target proteins.

\section{Cell proliferation determination by sulforhodamine B (SRB)}

Cell proliferation was measured by SRB kit (KeyGEN BioTECH, Nanjing, China). Cells were seeded in 96-well plate at the density of $1 \times 10^{3}$ cells/ well for $24 \mathrm{~h}$. Then the cells were treated with HLJDD $(5 \mathrm{mg} / \mathrm{mL}, 2.5 \mathrm{mg} /$ $\mathrm{mL}$ and $1.25 \mathrm{mg} / \mathrm{mL})$, paclitaxel $(6 \mu \mathrm{g} / \mathrm{mL})$ and cisplatin $(5 \mu \mathrm{g} / \mathrm{mL})$ respectively for the next 24,48 and $72 \mathrm{~h}$. After incubation, the cells were washed with $1 \times \mathrm{PBS}$ and fixed with $100 \mu \mathrm{L} \mathrm{50 \%} \mathrm{TCA} \mathrm{for} 1 \mathrm{~h}$ at $4{ }^{\circ} \mathrm{C}$. Then every $30 \mathrm{~s}$, we used $100 \mu \mathrm{L}$ washing solution A to wash cells for 2 times. $50 \mu \mathrm{L}$ of SRB dying solution was added to each well and incubated for $15 \mathrm{~min}$ at room temperature, protected from light. We used $100 \mu \mathrm{L}$ washing solution $\mathrm{B}$ to remove the unbound SRB and repeated it 5-10 times. $100 \mu \mathrm{L}$ dissolving solution was added and incubated at room temperature for $5 \mathrm{~min}$, protected from light. Absorbance was measured at $515 \mathrm{~nm}$. The inhibitory rate of cell proliferation was calculated according to the formula: ((control OD value-experimental OD value)/control OD value) $\times 100 \%[37]$.

\section{Cell cycle detection by flow cytometry analysis}

Cells were harvested after administration for $24 \mathrm{~h}$ and washed with cold PBS for two times. After fixed with ice-cold $70 \%$ ethanol at $4{ }^{\circ} \mathrm{C}$ overnight, cells were centrifuged at $2000 \mathrm{rpm}$ for $5 \mathrm{~min}$ and washed with cold PBS. Then cells were added with $500 \mu \mathrm{L}$ PBS which containing $50 \mu \mathrm{g} / \mathrm{mL}$ Ethidium Bromide (EB), $100 \mu \mathrm{g} / \mathrm{mL}$ RNase A and $0.2 \%$ Triton X-100. After incubation at $4{ }^{\circ} \mathrm{C}$ for $30 \mathrm{~min}$ in the dark place, DNA contents were evaluated by CytoFLEX LX flow cytometry analyzer (Beckman Coulter, Inc. 250S. Kraemer Boulevard Brea, CA 92,821, USA). The result was analyzed by Denovo FCS Express 6 software (De Novo Software, 207 N. Sierra Madre Blvd, Pasadena, CA 91,107, USA).

\section{Cell apoptosis measurement by flow cytometry analysis}

Cells were seeded in 6-well plates and treated with HLJDD $(5 \mathrm{mg} / \mathrm{mL}, 2.5 \mathrm{mg} / \mathrm{mL}$ and $1.25 \mathrm{mg} / \mathrm{mL})$, paclitaxel $(6 \mu \mathrm{g} / \mathrm{mL})$ and cisplatin $(5 \mu \mathrm{g} / \mathrm{mL})$ respectively for $24 \mathrm{~h}$. Cell apoptosis was measured by a FITC Annexin V Apoptosis Detection Kit (556547, BD Biosciences, San Jose, California, USA). Cells were washed twice with $1 \times$ cold PBS and stained with $5 \mu \mathrm{L}$ Annexin V-FITC 
and $5 \mu \mathrm{L}$ PI. After incubation at $4{ }^{\circ} \mathrm{C}$ in the dark place for $20 \mathrm{~min}$. The apoptosis was analyzed by DxFLEX flow cytometry analyzer (Beckman Coulter, Inc. 250S. Kraemer Boulevard Brea, CA 92821, USA).

\section{Statistical analysis}

All data were expressed as the mean \pm standard error of mean (SEM). Statistical differences among the different groups were evaluated by one-way ANOVA with Bonferroni's multiple comparison test with Graph Prism 5 software (GraphPad Software Inc., San Diego, CA, USA). $p<0.05$ was considered significant.

\section{Results}

\section{Construction of HLJDD potential active ingredients-targets} interaction network

The effect of TCM formula on disease depends on the relationship between the effective ingredients and their targets. We found out 35 HLJDD potential active ingredients (Table 1), 5 in Coptis chinensis Franch, 16 in Scutellaria baicalensis Georgi, 10 in Phellodendron amurense Rupr and 4 in Gardenia jasminoides J.Ellis. In the Table 1, the repeated potential active ingredients between Coptis chinensis Franch and Phellodendron amurense Rupr were MOL000622, MOL000785 and MOL001454. Moreover, the repeated potential active ingredients between Scutellaria baicalensis Georgi and Phellodendron amurense Rupr was MOL000358. Previous data showed that ingredients such as Coptisine, Palmatine, berberine, wogonin, etc. had been confirmed in mass spectrometry (MS) and MS/MS data experiments to identify the prototype components in rat plasma after oral administration of HLJDD [38] and latter three ingredients were well separated by High Performance Liquid Chromatography (HPLC) fingerprint method [39]. It indicated that the potential active ingredients we had obtained were worthy of further research. Then we searched related targets of HLJDD potential active ingredients. The number of related targets of Coptis chinensis Franch, Scutellaria baicalensis Georgi, Phellodendron amurense Rupr and Gardenia jasminoides J.Ellis were 83, 348, 284 and 117, respectively. Because there were many duplicate targets in the ingredients of TCM, we had recounted the number of targets related to the potential active ingredients of Coptis chinensis Franch, Scutellaria baicalensis Georgi, Phellodendron amurense Rupr and Gardenia jasminoides J.Ellis which were $39,93,81$ and 88 , respectively. To visualize the relationship, we built the potential active ingredientsrelated targets interaction network by Cytoscape software. As it showed in Fig. 1, different color represented potential active ingredients of Coptis chinensis Franch, Scutellaria baicalensis Georgi, Phellodendron amurense Rupr and Gardenia jasminoides J.Ellis. The middle pink color part represented the common targets set of potential active ingredients related targets. For the duplicated targets corresponding to different potential active ingredients in HLJDD, this figure only showed the one target which linked related potential active ingredients.

Screening the core targets between HLJDD potential active ingredients related targets and OSCC related targets

We used Bisogenet in Cytoscape to make PPI network diagrams including OSCC related targets, HLJDD potential active ingredient related targets of Phellodendron amurense Rupr, Coptis chinensis Franch, Scutellaria baicalensis Georgi and Gardenia jasminoides J.Ellis. In Fig. 2A, the nodes of Phellodendron amurense Rupr, Coptis chinensis Franch, Scutellaria baicalensis Georgi, Gardenia jasminoides J.Ellis and OSCC related targets were $3228,2696,3844,4701$ and 1771 , respectively. The number of edges were 79,308, 64,761,94,743, 117,398 and 37,054, respectively. Through the Merge Function in the toolbar of Cytoscape, we got the intersection network diagram of these five PPIs which contained 803 nodes and 19,787 edges.

After performing a topological analysis of the network in the CytoNCA plug-in of Cytoscape, we found that each gene had almost 48.174 neighbors (Table 2). After calculating median of degree value, we imported twice the median value and the total number of nodes, the system automatically marked eligible nodes with yellow color which called core targets (Fig. 2B and C). Finally, we obtained 52 core targets which were more than twice the median of degree value (Table 3). The greater of degree value meant the more nodes interaction with this gene. Moreover, we also rebuilt the core target PPI network diagram (Fig. 2D).

\section{Enrichment analysis of core targets}

Using above exported core targets, we combined ClueGO plug-in in Cytoscape and DAVID website (https:// david.ncifcrf.gov/summary.jsp) for enrichment analysis including Gene Ontology (GO) (Biological Process (BP), Cellular Component (CC) and Molecular Function (MF)) and Kyoto Encyclopedia of Genes and Genomes (KEGG) analysis (Fig. 3G). GO analysis of core targets was performed at $p \mathrm{~V} \leq 0.05$, containing GO-BP (Fig. 3A), GO-CC (Fig. 3C) and GO-MF (Fig. 3E). Because we defined the filter condition of $\mathrm{pV} \leq 0.05$ before doing the enrichment analysis, the specific $p$ value was not displayed in the exported data. But the DAVID website just made up for this shortcoming. After exporting $p$ values from DAVID website, we sorted them from the smallest to the largest and took the TOP 30 to make advanced 
Table 1 Potential active ingredients and the number of their related targets in HLJDD formula

\begin{tabular}{|c|c|c|c|c|c|}
\hline Mol ID & Molecule Name & Structure & $\begin{array}{l}\text { OB } \\
(\%)\end{array}$ & Source & $\begin{array}{c}\text { Number of } \\
\text { targets }\end{array}$ \\
\hline $\begin{array}{c}\text { Coptis } \\
\text { chinensis } \\
\text { Franch } \\
\text { (5 Mol IDs): } \\
\text { MOL000360- } \\
1867\end{array}$ & $\begin{array}{l}\text { FER (3-(4-hydroxy-3- } \\
\text { methoxy-phenyl) } \\
\text { prop-2-enoic acid) }\end{array}$ & & 39.55852 & & 21 \\
\hline MOL000622 & Magnograndiolide & & 63.70888 & & 2 \\
\hline MOL000785 & Palmatine & & 64.60111 & $\begin{array}{c}\text { Coptis chinensis } \\
\text { Franch }\end{array}$ & 24 \\
\hline MOL001454 & Berberine & & 36.86125 & & 29 \\
\hline MOL001867 & $\begin{array}{l}\text { Isovanillin (3- } \\
\text { Hydroxy-4- } \\
\text { methoxybenzaldehyde) }\end{array}$ & & 31.0063 & & 7 \\
\hline $\begin{array}{c}\text { Scutellaria } \\
\text { baicalensis } \\
\text { Georgi } \\
\text { (16 Mol IDs): } \\
\text { MOL000018- } \\
1689\end{array}$ & (+/-)-Isoborneol & & 86.98413 & & 19 \\
\hline MOL000122 & 1,8-cineole & & 39.72922 & & 15 \\
\hline
\end{tabular}

bubble charts of GO-BP (Fig. 3B), GO-CC (Fig. 3D), GO-MF (Fig. 3F) and KEGG pathway analysis (Fig. 3H).

In Fig. $3 \mathrm{~A}$ and $\mathrm{B}$, we got 1156 items from ClueGO and 296 items from DAVID website for GO-BP. Based on top
30 biological processes presented in Fig. 3B, it suggested that HLJDD might involve in some typical biological processes, such as negative regulation of apoptotic processes; cell cycle arrest; G2 / M switch of cycle; positive 
Table 1 (continued)

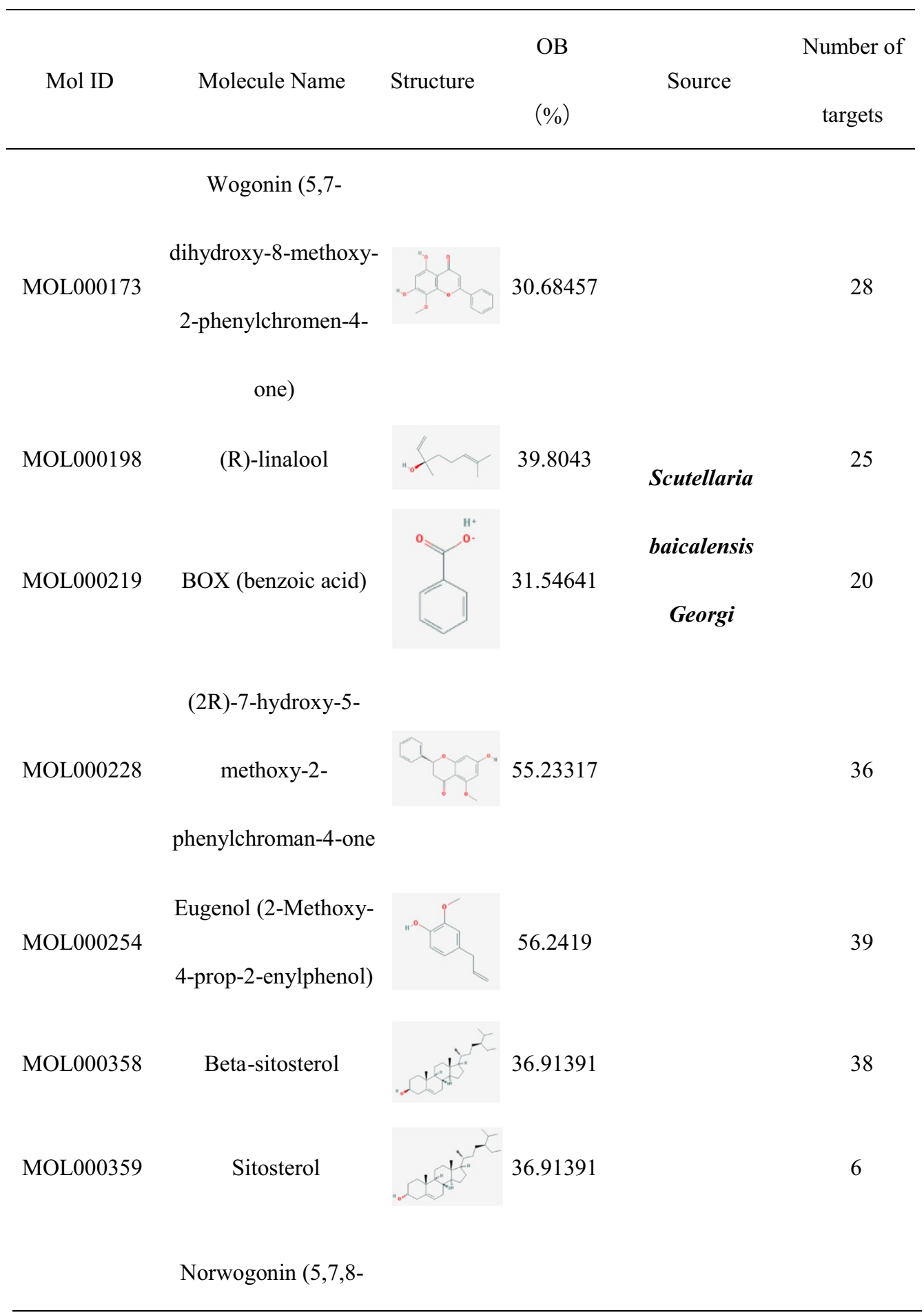

regulation of DNA replication; G1/S switch of mitotic cell cycle; activation of MAPK activity, etc. As for GO-CC, there were 10 items from ClueGO and 48 items from DAVID website (Fig. 3C and D). It revealed that HLJDD might take part in some $\mathrm{CC}$, such as mitotic spindle, nuclear chromosome, telomeric region, etc. Moreover, we got 51 items from ClueGO and 101 items from DAVID website for GO-MF. According to the TOP30, 
Table 1 (continued)

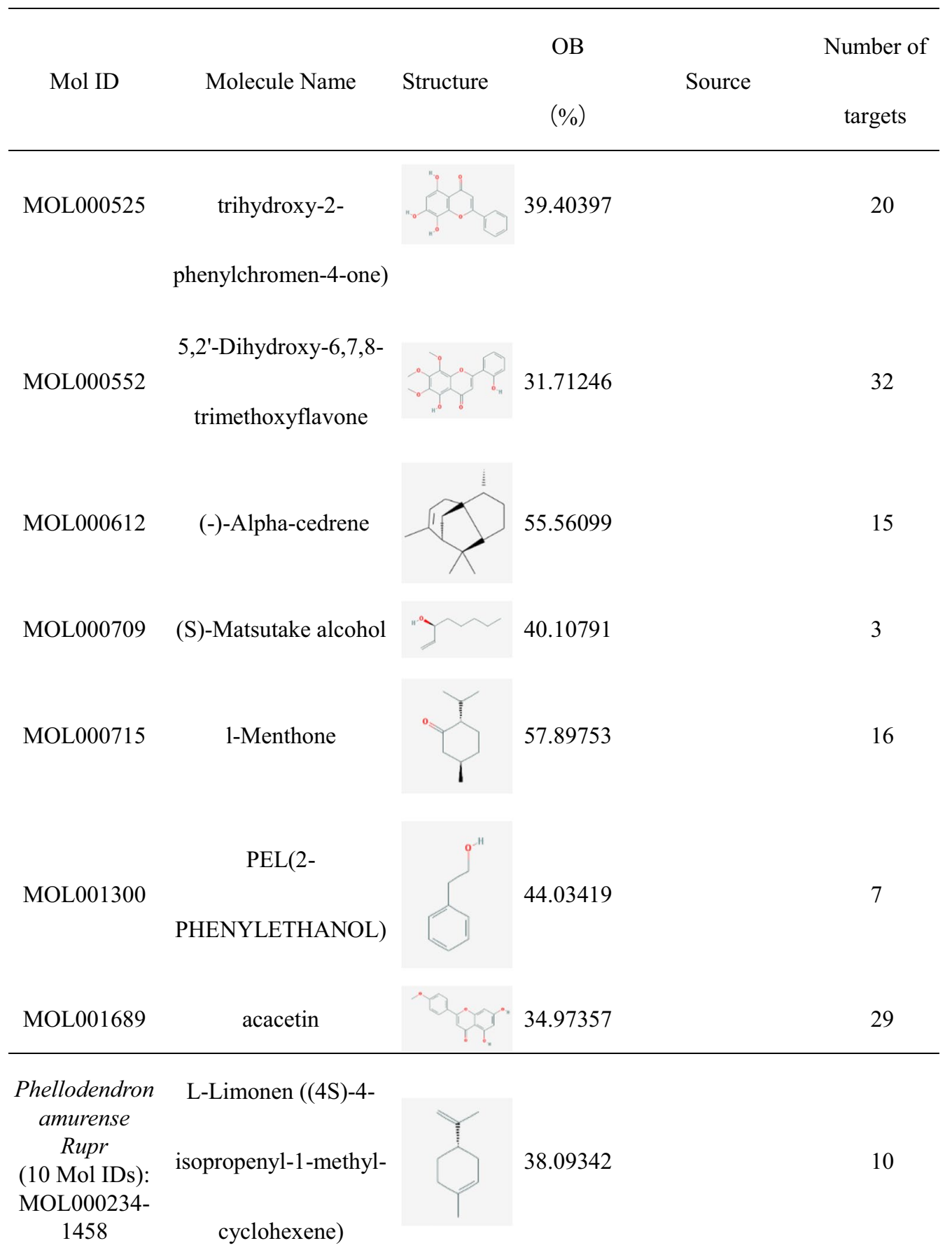

HLJDD might affect transcription factor binding, protein kinase binding, kinase binding and activity, etc. (Fig. 3E and F). Based on the enrichment of these molecular function, it was necessary to detect of protein phosphorylation and kinase activity in the further experiments.
KEGG pathway enrichment results indicated that HLJDD might work through cell apoptosis pathway, PI3K-AKT, mitogen-activated protein kinase (MAPK) and nuclear factor-kappa B (NF-kB) etc. signaling pathway to produce the anti-tumor effect on OSCC. Taken together, 
Table 1 (continued)

\begin{tabular}{|c|c|c|c|c|c|}
\hline \multirow{3}{*}{ Mol ID } & \multirow{3}{*}{ Molecule Name } & & OB & & Number of \\
\hline & & Structure & \multicolumn{3}{|c|}{ Source } \\
\hline & & & $(\%)$ & & targets \\
\hline MOL000348 & 1-enyl]-2,6- & & 49.14734 & amurense Rupr & 31 \\
\hline & dimethoxyphenol & & & & \\
\hline MOL000358 & Beta-sitosterol & & 36.91391 & & 40 \\
\hline MOL000449 & Stigmasterol & & 43.82985 & & 42 \\
\hline MOL000622 & Magnograndiolide & & 63.70888 & & 5 \\
\hline MOL000785 & Palmatine & & 64.60111 & & 23 \\
\hline MOL000787 & Fumarine & & 59.2625 & & 40 \\
\hline MOL000790 & Isocorypalmine & & 35.76844 & & 53 \\
\hline MOL001454 & Berberine & & 36.86125 & & 26 \\
\hline MOL001458 & Coptisine & & 30.67185 & & 14 \\
\hline $\begin{array}{c}\text { Gardenia } \\
\text { jasminoides } \\
\text { J.Ellis (4 Mol IDs): } \\
\text { MOL000098-1941 }\end{array}$ & Quercetin & & 46.43335 & & 78 \\
\hline
\end{tabular}


Table 1 (continued)

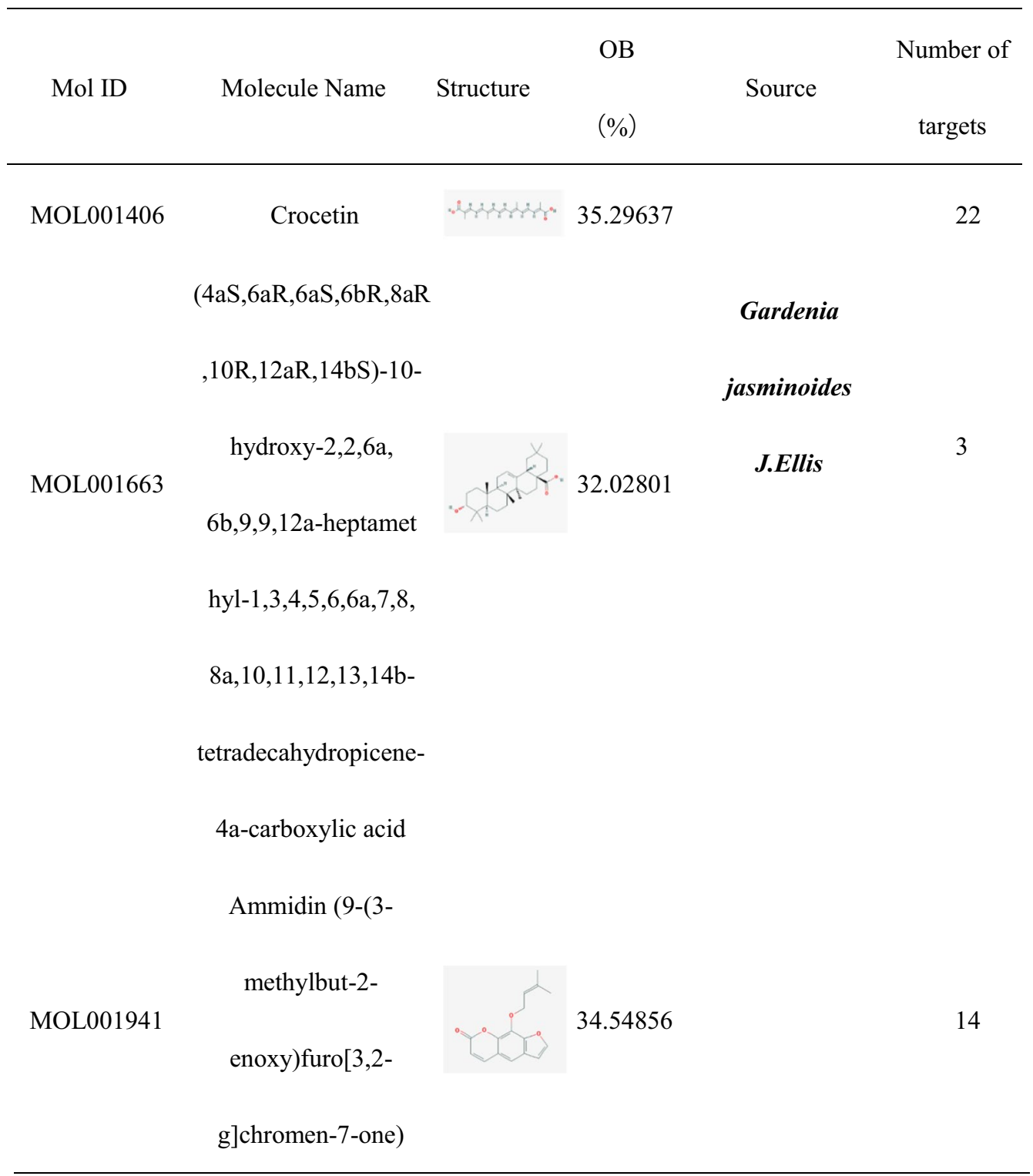

enrichment analysis of core targets provided the experimental directions for future verification.

\section{The inhibitory effect of HLJDD on the growth of OSCC cell lines}

With the measurement of sulforhodamine B (SRB), we detected the inhibitory rate of HLJDD on CAL-27 and SCC-25 OSCC cell lines. In Fig. 4, the inhibitory effects of HLJDD (1.25 mg/mL, $2.5 \mathrm{mg} / \mathrm{mL}, 5 \mathrm{mg} / \mathrm{mL}), 6 \mu \mathrm{g} / \mathrm{mL}$ paclitaxel and $5 \mu \mathrm{g} / \mathrm{mL}$ cisplatin on cells were increased in time dependent manners. But there was no dosedependent change on HLJDD. Compared with paclitaxel or cisplatin, HLJDD had similar inhibitory effect and after administration $24 \mathrm{~h}$ the effects of three concentrations of HLJDD on SCC cells were higher than paclitaxel or cisplatin. Therefore, it was worth to detect the further mechanism after administration for $24 \mathrm{~h}$ with three different concentrations of HLJDD and two positive drugs (paclitaxel and cisplatin) on SCC-25 and CAL-27 cell lines.

\section{HLJDD promoted late stage of cell apoptosis}

The result of SRB indicated that HLJDD inhibited proliferation of OSCC cell lines. Based on the enrichment results, we proposed HLJDD may involve in cell cycle and apoptosis, then inhibit the proliferation of OSCC cell 


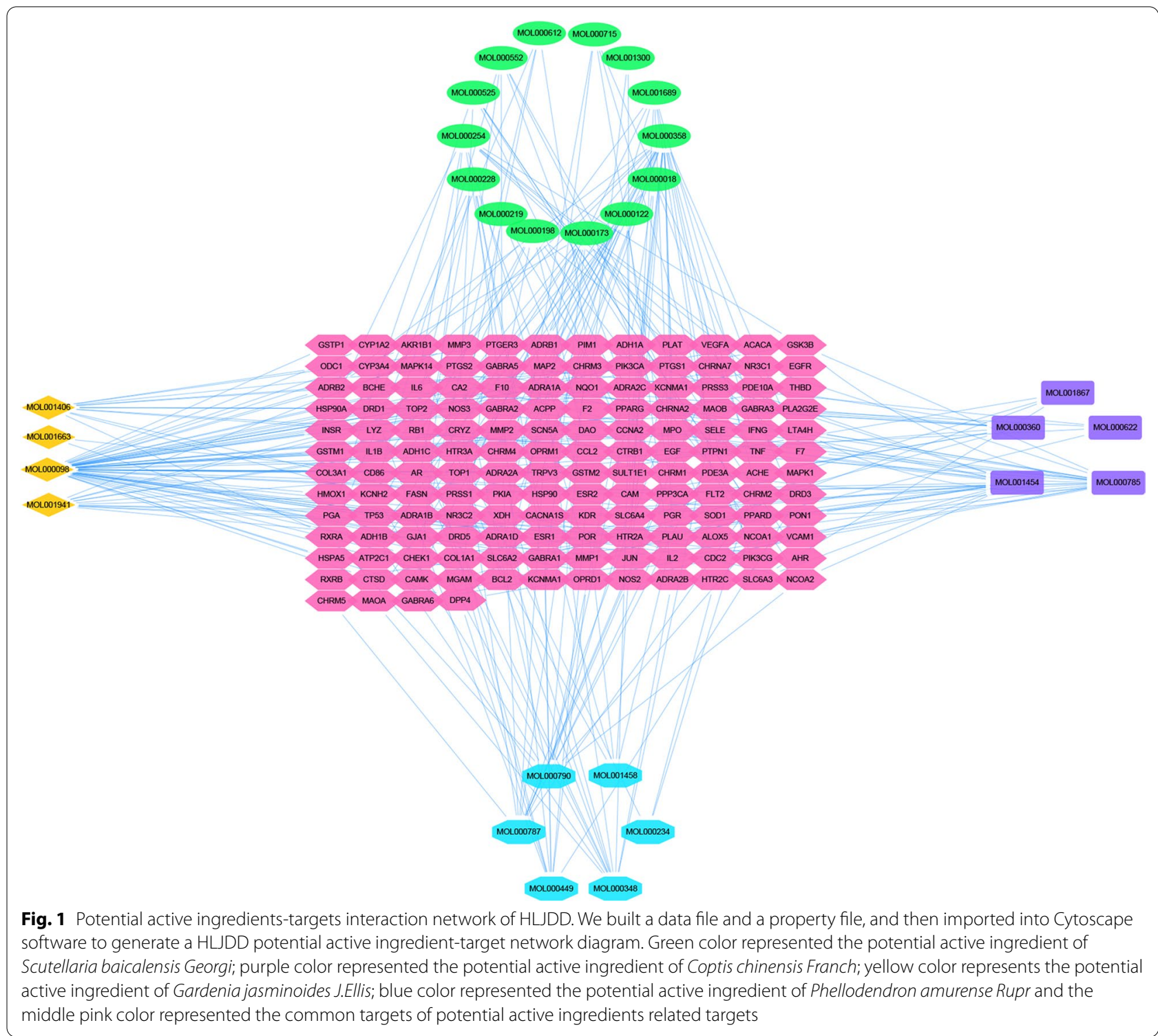

lines. We performed the Annexin-V FITC/PI staining to detect the apoptosis of SCC-25 cells after administration for $24 \mathrm{~h}$ (Fig. 5). Comparing with control group, percentages of late-stage apoptosis in $2.5 \mathrm{mg} / \mathrm{mL}$ HLJDD group and paclitaxel group were significantly increased, while others were increased without significance. Interestingly, the percentage of late-stage apoptosis in $2.5 \mathrm{mg} / \mathrm{mL}$ HLJDD group was higher than that in $1.25 \mathrm{mg} / \mathrm{mL}$ and $5 \mathrm{mg} / \mathrm{mL}$ HLJDD groups, and even cisplatin group. Compared to paclitaxel group, the percentages of late-stage apoptosis in $1.25 \mathrm{mg} / \mathrm{mL}$ and $5 \mathrm{mg} / \mathrm{mL}$ HLJDD groups were significantly reduced, while in $2.5 \mathrm{mg} / \mathrm{mL}$ HLJDD group there had no significant difference. It suggested
HLJDD had potential to promote apoptosis, the effect of $2.5 \mathrm{mg} / \mathrm{mL}$ HLJDD was similar with that of paclitaxel.

\section{HLJDD inhibited G1 phase and arrested in S phase on cell division cycle}

From above results, we confirmed that HLJDD inhibited the growth of OSCC and promoted the cell apoptosis. It was still unclear whether it had an influence on cell cycle. Based on network pharmacological enrichment analysis results (cell cycle arrest; cell proliferation, etc.) It was necessary to verify the effect of HLJDD on cell cycle to provide evidence to explain the effect of HLJDD on cell proliferation. 


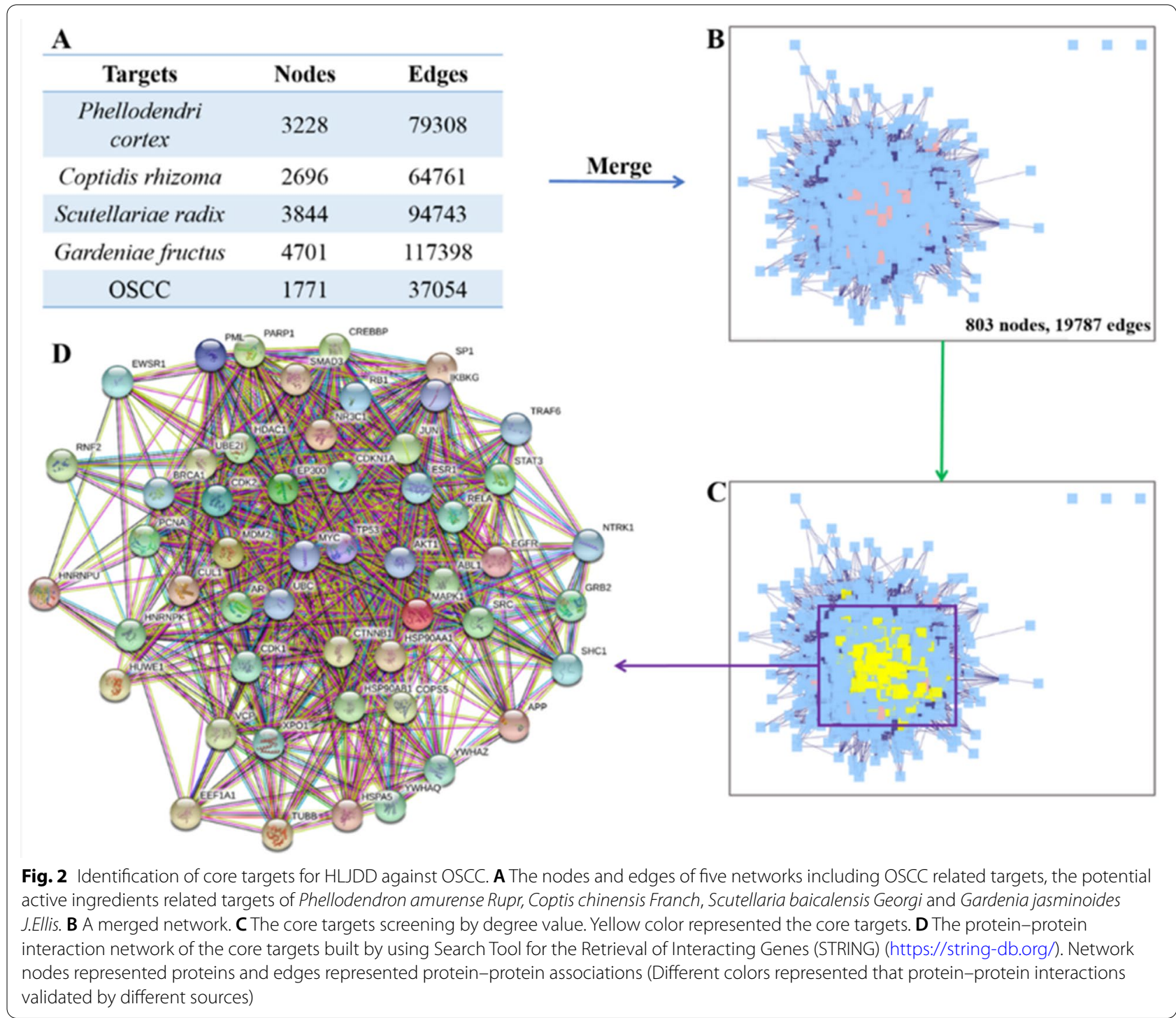

Table 2 The topological parameters of merged network (HLJDD potential active ingredients related targets_OSCC related targets protein-protein interaction network)

\begin{tabular}{|c|c|c|c|}
\hline Parameters & Results & Parameters & Results \\
\hline Clustering coefficient & 0.284 & Number of nodes & 803 \\
\hline $\begin{array}{l}\text { Connected compo- } \\
\text { nents }\end{array}$ & 4 & Network density & 0.060 \\
\hline Network diameter & 4 & $\begin{array}{l}\text { Network heteroge- } \\
\text { neity }\end{array}$ & 0.910 \\
\hline Network radius & 3 & Isolated nodes & 3 \\
\hline Network centralization & 0.581 & Number of self-loops & 445 \\
\hline Shortest paths & $639200(99 \%)$ & Multi-edge node pairs & 0 \\
\hline $\begin{array}{l}\text { Characteristic path } \\
\text { length }\end{array}$ & 2.070 & Analysis time (sec) & 0.446 \\
\hline $\begin{array}{l}\text { Avg. number of } \\
\text { neighbors }\end{array}$ & 48.174 & & \\
\hline
\end{tabular}

In Fig. 6, compared with control group, HLJDD $(1.25 \mathrm{mg} / \mathrm{mL}, 2.5 \mathrm{mg} / \mathrm{mL}, 5 \mathrm{mg} / \mathrm{mL})$ and $6 \mu \mathrm{g} / \mathrm{mL}$ paclitaxel significantly reduced G1 phase (DNA pre-synthesis phase), especially $2.5 \mathrm{mg} / \mathrm{mL}$ HLJDD. Moreover, $2.5 \mathrm{mg} /$ mL HLJDD and paclitaxel were significantly elevated the percentages $S$ phase (DNA synthesis phase). It revealed that $2.5 \mathrm{mg} / \mathrm{mL}$ HLJDD promoted $\mathrm{S}$ phase arrest rather than $1.25 \mathrm{mg} / \mathrm{mL}$ and $5 \mathrm{mg} / \mathrm{mL}$ HLJDD. Altogether, $2.5 \mathrm{mg} / \mathrm{mL}$ HLJDD had more similar effect to paclitaxel, which reduced proportion of G1 phase and increased proportion of $\mathrm{S}$ phase. All above, $2.5 \mathrm{mg} / \mathrm{mL}$ HLJDD interfered with cell cycle by DNA synthesis inhibition, $S$ phase arrest and consequently suppressed cell proliferation. It was consistent with the biological process enrichment analysis result of network pharmacology. 
Table 3 The core targets of merged network (HLJDD potential active ingredients related targets-OSCC related targets protein-protein interaction network)

\begin{tabular}{|c|c|c|c|c|c|}
\hline Name & Degree value & Name & Degree value & Name & Degree value \\
\hline RNF2 & 61 & $\mathrm{SHC1}$ & 59 & RELA & 75 \\
\hline GRB2 & 87 & ABL1 & 66 & HSP90AB1 & 86 \\
\hline NR3C1 & 71 & $C M L 1$ & 73 & PARP1 & 64 \\
\hline MDM2 & 93 & STAT3 & 65 & JUN & 77 \\
\hline CREBBP & 73 & BRCA1 & 93 & PML & 59 \\
\hline COPS5 & 75 & HUWE1 & 72 & AKT1 & 72 \\
\hline SRC & 75 & MAPK1 & 60 & CTNNB1 & 78 \\
\hline UBC & 93 & NTRK1 & 152 & CDK1 & 56 \\
\hline UBE2I & 70 & EEF1A1 & 55 & TP53 & 225 \\
\hline PCNA & 55 & EGFR & 126 & CDK2 & 102 \\
\hline EP300 & 97 & IKBKG & 61 & EWSR1 & 64 \\
\hline$A R$ & 195 & XPO1 & 64 & CDKN1A & 64 \\
\hline APP & 80 & YWHAZ & 79 & TRAF6 & 66 \\
\hline SP1 & 59 & HNRNPK & 54 & SMAD3 & 70 \\
\hline YWHAQ & 54 & HNRNPU & 54 & ESR1 & 144 \\
\hline HDAC1 & 73 & HSPA5 & 67 & MYC & 94 \\
\hline VCP & 79 & HSP90AA1 & 101 & & \\
\hline TUBB & 67 & RB1 & 67 & & \\
\hline
\end{tabular}

\section{HLJDD inhibited the migration of OSCC}

We performed wound healing assay to illustrate the migration of cells. In Fig. 7, the inhibitory effects of HLJDD on CAL-27 cell line were in dose-dependent manner and more obvious than that on SCC- 25 cell line. On two cells, the inhibitory effects of $1.25 \mathrm{mg} / \mathrm{mL}$ HLJDD and cisplatin were similar, while $5 \mathrm{mg} / \mathrm{mL}$ HLJDD and paclitaxel presented stronger inhibitory effect than others. Stated thus, HLJDD significantly suppressed the migration of OSCC.

\section{HLJDD inhibited phosphorylation of ERK1/2 and NF-KB p65 (S468)}

HLJDD inhibited the late stage of apoptosis and suppressed the cell cycle by arresting $S$ phase. Meanwhile, HLJDD inhibited the migration of OSCC but the mechanism was still unknown. The results of network pharmacological enrichment analysis provided directions for the exploration of these biological processes. Then we focused on the TOP30 of KEGG pathway enrichment results. HLJDD reduced the phosphorylation of ERK1/2 in dose-dependent manners on both SCC-25 and CAL27 cell lines (Fig. 8A and B). Additionally, $5 \mathrm{mg} / \mathrm{mL}$ HLJDD showed nearly $40 \%$ inhibitory rate on the phosphorylation of NF-kB p65 (S468) both SCC-25 and CAL27 cell lines. Interestingly, on SCC-25 cell line, $\mathrm{p}-\mathrm{NF}-\mathrm{kB}$ p65 reduced in a dose-dependent manner, which did not find on CAL-27 cell line. Moreover, we found $5 \mathrm{mg} / \mathrm{mL}$ HLJDD inhibited the phosphorylation of IKK $\alpha+\beta$ on CAL-27 not SCC-25. At the same time, we checked other phosphorylation sites of NF-kB p65, including S529 and S276, but failed to find the significant change (Additional file 1: Fig. S1 A and B), suggested that HLJDD specifically inhibited phosphorylation of S468 site. It was obvious that the paclitaxel had a higher inhibitory effect on CAL-27 and SCC-25 cell lines than that of HLJDD, but the inhibitory effect of $5 \mathrm{mg} / \mathrm{mL}$ HLJDD on phosphorylation was almost same like paclitaxel. Altogether, HLJDD might inhibit p-ERK1/2 and p-NF-kB p65 (S468) to play a therapeutic role on OSCC.

(See Figure On Next Page)

Fig. 3 The enrichment analysis of Gene Ontology (GO) and Kyoto Encyclopedia of Genes and Genomes (KEGG) pathway. A Biological process results in $\mathrm{GO}$ enrichment analysis (from ClueGO). Different colors represented different biological processes. If a gene was involved in different biological processes, it would show the proportion of different colors in the pie chart. B Biological process results in GO enrichment analysis (from DAVID). Rich Factor represented the degree of enrichment. The size of the bubble represented the number of genes enriched in one kind of biological process and the color represented the $p$ value. The smaller $p$ value represented enrichment more significant. C Cellular component results in GO enrichment analysis (from ClueGO). D Cellular component results in GO enrichment analysis (from DAVID). E Molecular function results in GO enrichment analysis (from ClueGO). F Molecular function results in GO enrichment analysis (from DAVID). G KEGG enrichment analysis results (from ClueGO). $\mathbf{H}$ Selected pathway results of KEGG enrichment analysis (from DAVID) 
A
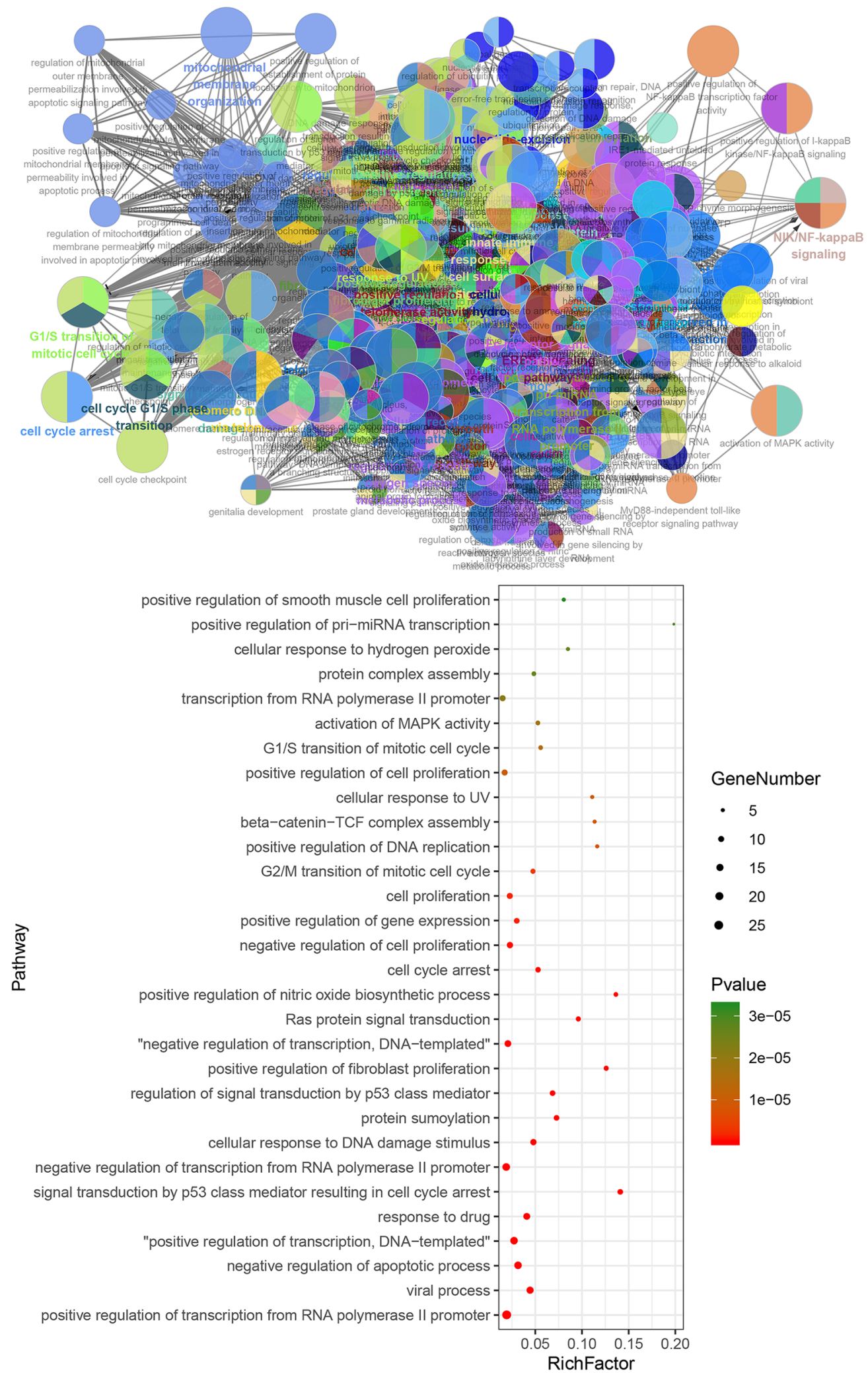
C

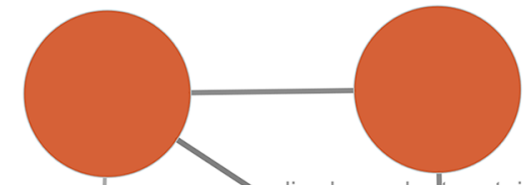

serine/threonine protelin-dependent protein kinase

kinase complex

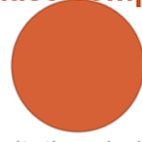

mitotic spindle

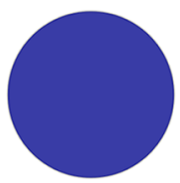

protein kinase complex

PML body
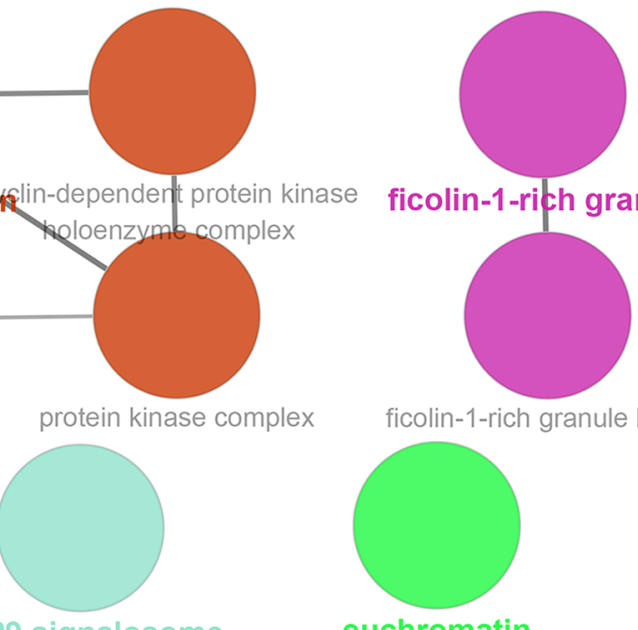

ficolin-1-riph granule

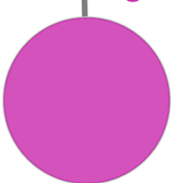

1-rich granule lumen

D

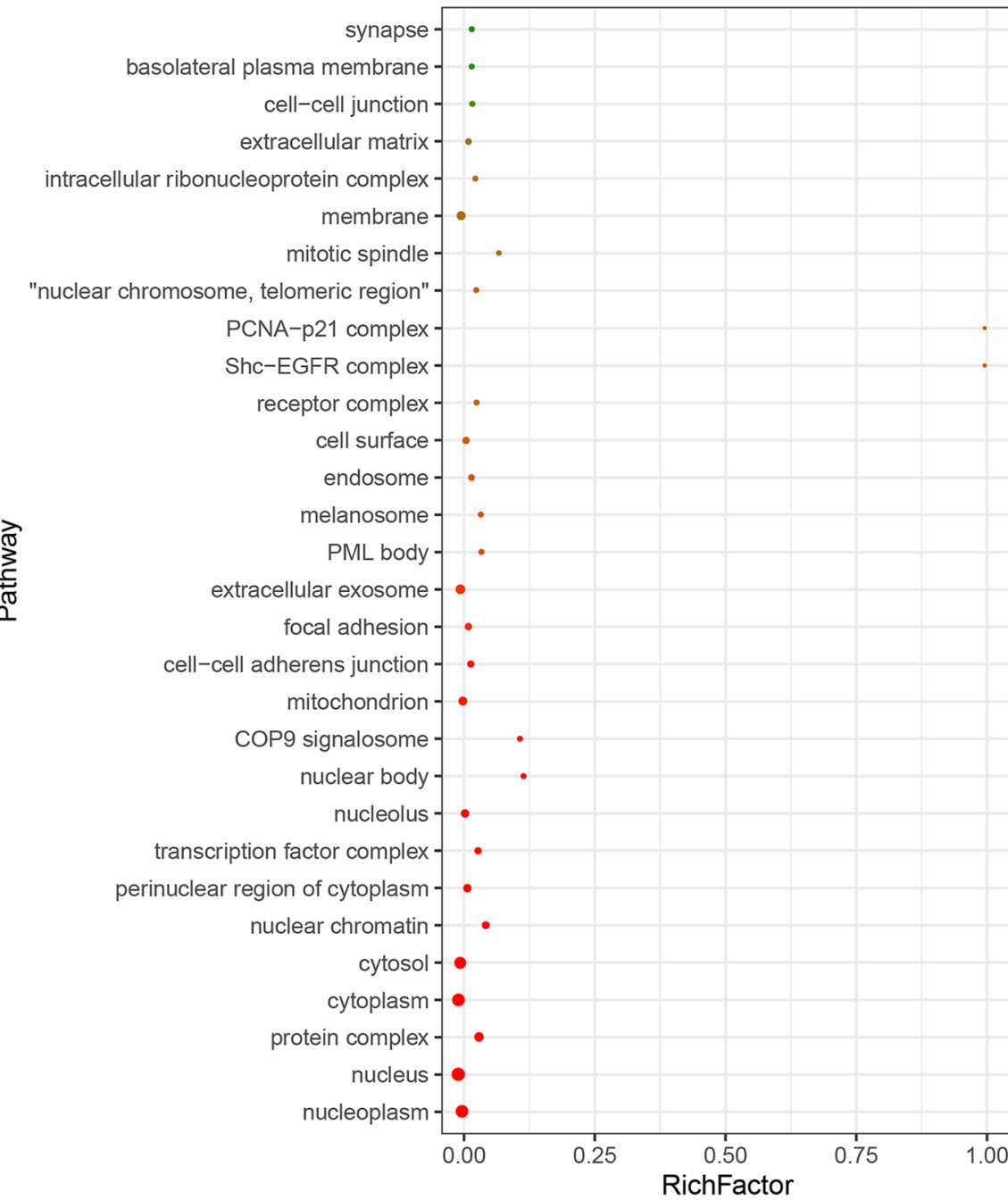

GeneNumber

- 10

- 20

- 30

- 40

Pvalue

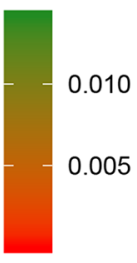

Fig. 3 continued 
$\mathbf{E}$

F
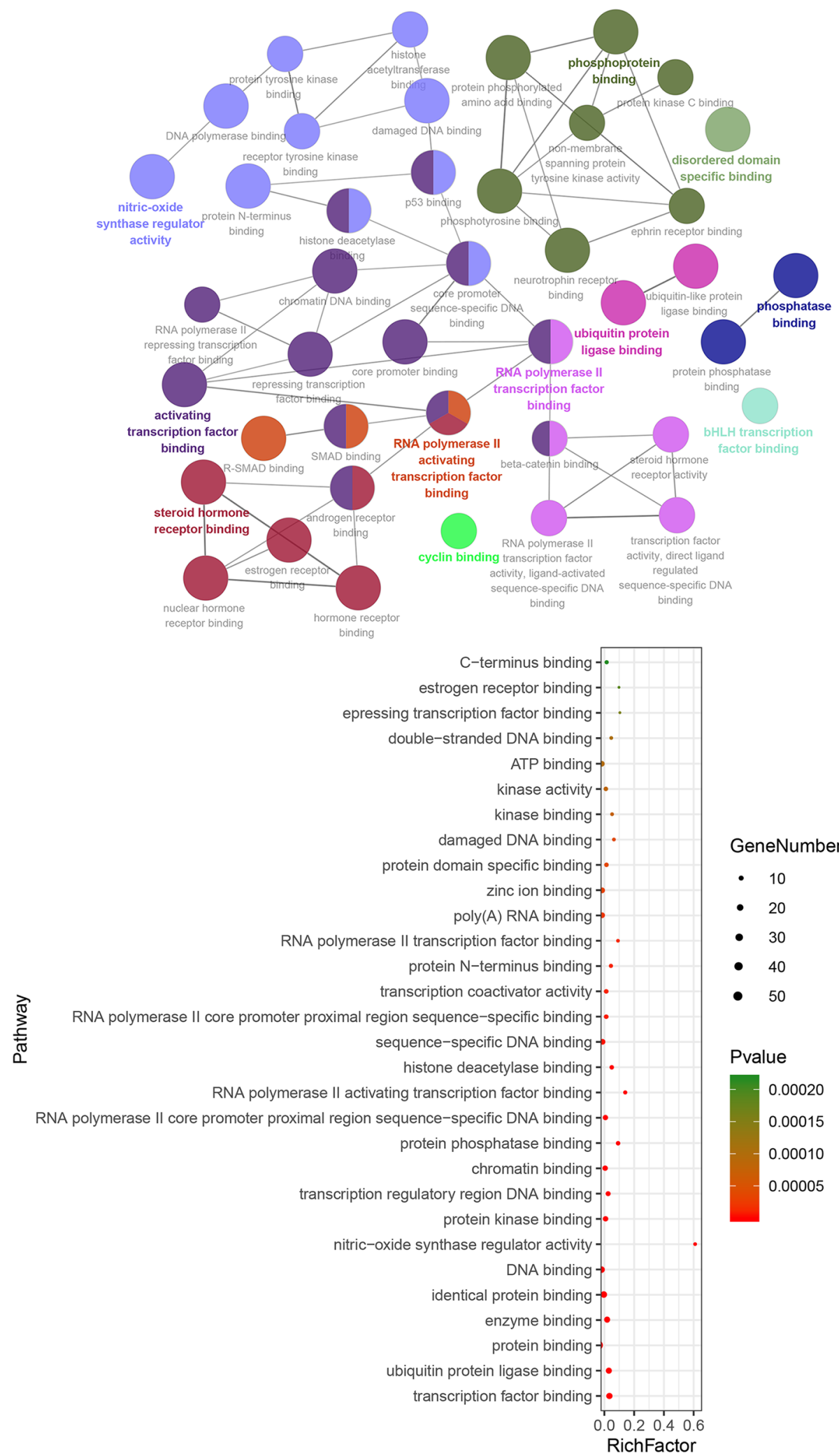

Fig. 3 continued 


\section{G}

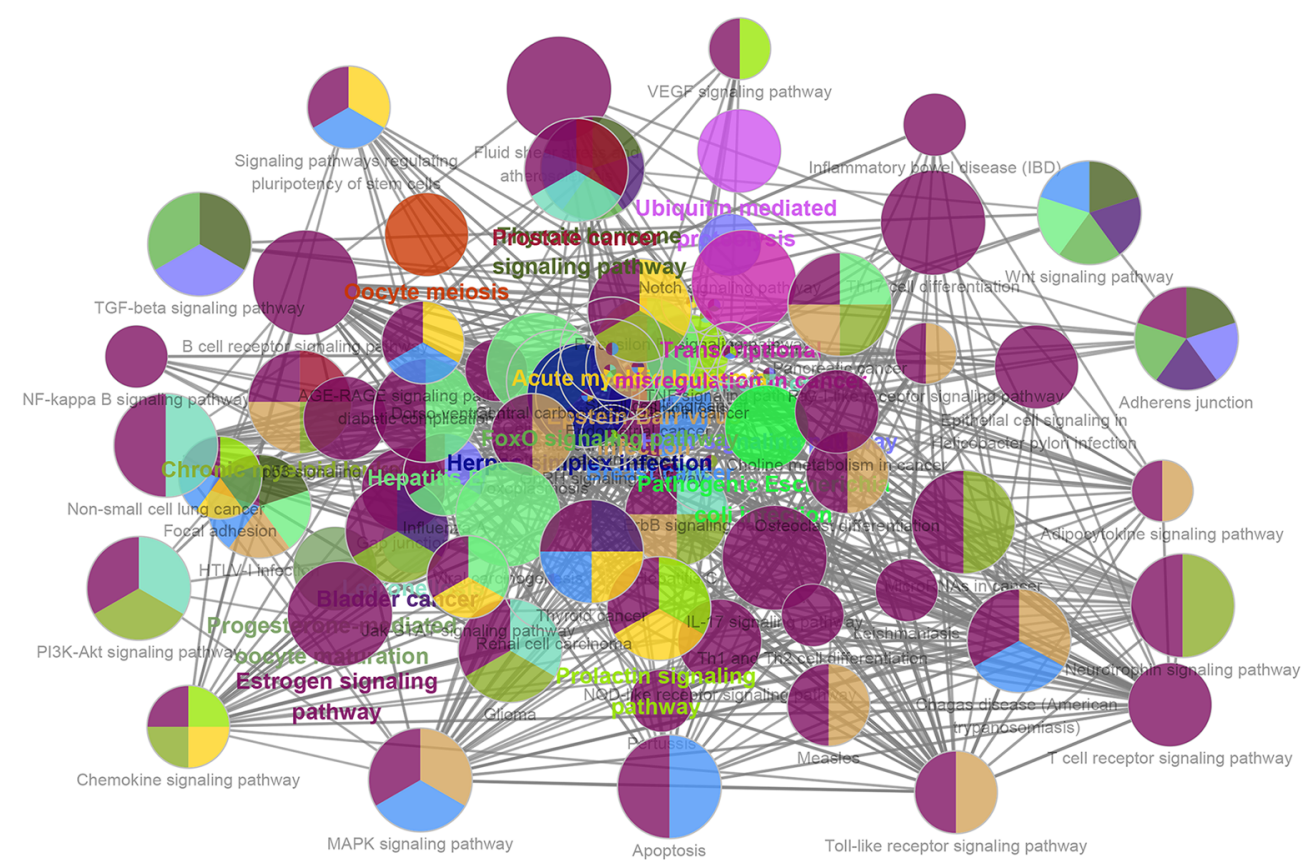

H

Top 30 of Pathway Enrichment

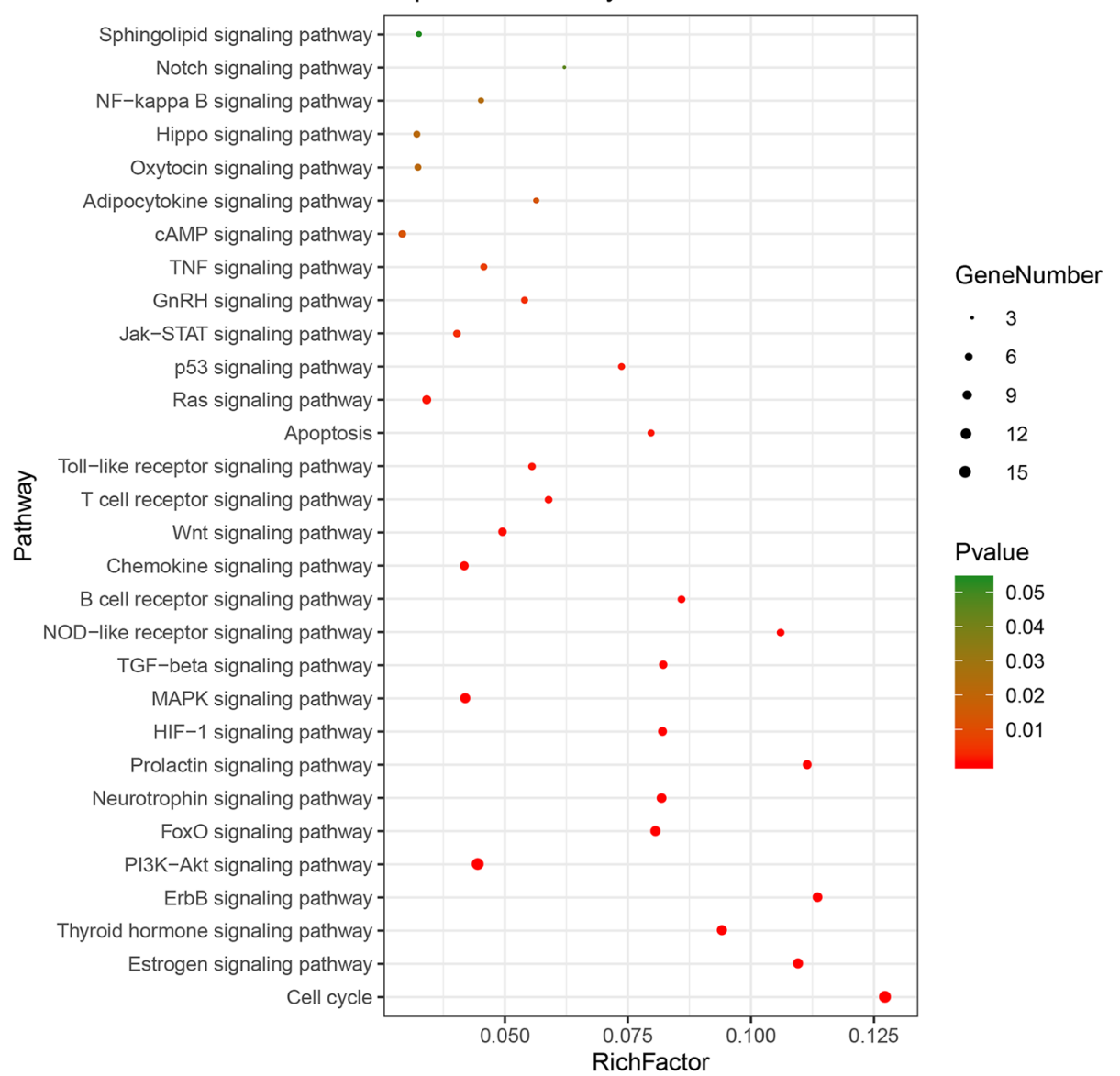

Fig. 3 continued 

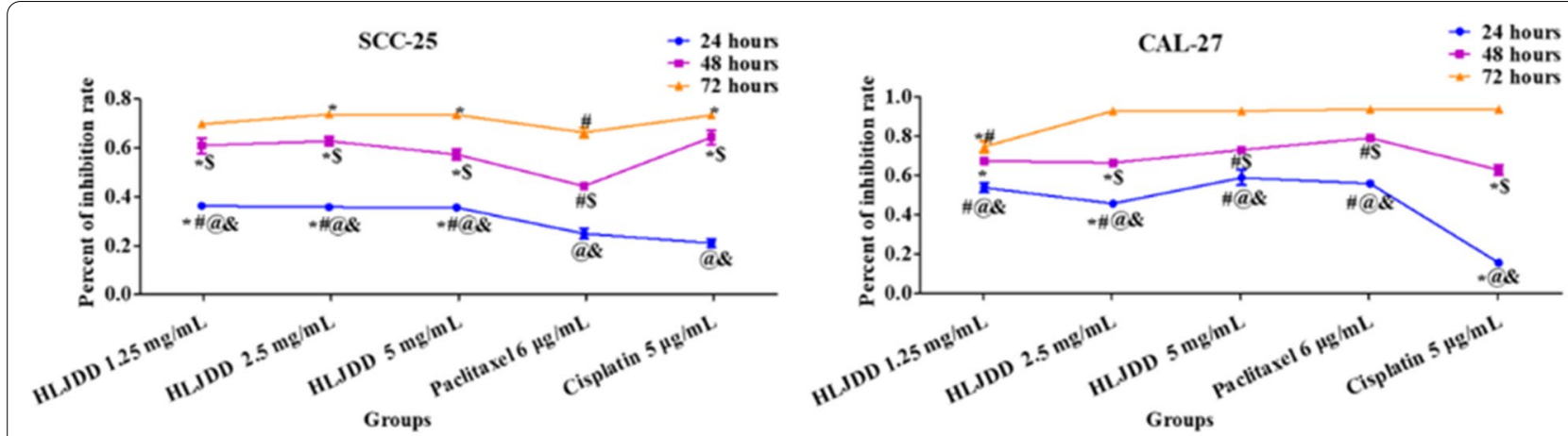

Fig. 4 The inhibitory effects of HLJDD, paclitaxel and cisplatin on SCC-25 and CAL-27 cell lines were detected by sulforhodamine B (SRB) measurement after administration for 24,48 and $72 \mathrm{~h} . \mathrm{n}=6 .{ }^{*} p<0.05 \mathrm{vs}$. paclitaxel group in different time points. \# $p<0.05 \mathrm{vs}$. cisplatin group in different time points. @ $p<0.0524$ h vs. 48 h. $\$ p<0.0548$ h vs. 72 h. $\& p<0.0524$ h vs. 72 h

\section{Discussion}

In our study, we explored the Huanglianjiedu Decoction (HLJDD) potential mechanism on oral squamous cell carcinoma (OSCC) based on network pharmacology and discovered the antitumor effect of HLJDD on OSCC cell lines. According to the enrichment analysis of core targets by Gene Ontology (GO) (Biological Process (BP), Cellular Component (CC) and Molecular Function (MF)) and Kyoto Encyclopedia of Genes and Genomes (KEGG) analysis, we found the effects of HLJDD on OSCC involved in cell proliferation, apoptosis and cell cycle. Additionally, we found several relative signaling pathways including mitogen-activated protein kinase/extracellular regulated protein kinases (MAPK/ERK) pathways, nuclear factor-kappa $\mathrm{B}(\mathrm{NF}-\mathrm{kB})$ pathway and so on. Further in vitro experiments, we confirmed that HLJDD inhibited cell proliferation on CAL-27 and SCC-25 cell by promoting the late apoptosis, inhibiting the G1 phase (pre-DNA synthesis) and arresting the $S$ phase in the cell cycle. HLJDD significantly inhibited phosphate-extracellular regulated protein kinases1/2 (p-ERK1/2), p-NF-kB p65 (S468). These results suggest that HLJDD could play a therapeutic role in OSCC via inhibiting p-ERK1/2 and p-NF-kB p65 (S468).

Network pharmacology develops rapidly on basis of omics and large databases which provide the basic data to investigators for further analysis. In addition, the prediction of drug targets is another highlight of network pharmacology [40]. More and more studies used network pharmacology to investigate the effect of traditional Chinese medicine (TCM) on diseases. Based on pharmacokinetics datasets, prediction and screening by network pharmacology, Yue et al. successfully applied the molecular network to explain the mechanism of Angelica safflower on blood stasis syndrome [41]; Wang et al. used bioinformatics and network pharmacology to clarify the active ingredients, targets and pathways of Tianfoshen oral solution effectively worked on colorectal cancer [42]; Wu et al. applied databases, bioinformatics and network pharmacology to establish PPI networks and screened out the targets of curcumin on interstitial cystitis [43]. But network pharmacology also had disadvantages, such as its uncertainty and too wide coverage, which require more experiments to verify its accuracy. Even some items don't quite fit for human species.

The GO and KEGG pathway enrichment analysis of core targets provided a direction to explore the antitumor effect and mechanism of HLJDD on OSCC. The KEGG enrichment analysis was consistent with GO analysis about cell cycle and apoptosis. Besides, we focused on some pathways of TOP30. Firstly, we verified PI3K-AKT which had high Rich Factor. But the expression of p-AKT and AKT1/2/3 did not change after administration detected by western blot. It suggested the effect of HLJDD may not involve in PI3K-AKT pathway (Additional file 1: Fig. S1A and B). According to GO-BP and GO-CC enrichment results, HLJDD may involve in the activation of MAPK, kinase activity and binding. Therefore, we detected the expression of MAPK family (p38 and JNK) and found that the expression of p-p38 was increased after administration on both SCC-25 and CAL-27, while the expression of JNK showed no band detected by western blot on CAL-27 (the reason may relate to the administration for $24 \mathrm{~h}$ ) (Fig. 8, Additional file 1: Fig. S1 A and B). Wu et al. verified the anticancer properties of pristimerin on SCC- 25 and CAL27, which are related to the inhibition of MAPK/ ERK1/2 and AKT pathway [44]. The reason we did not get similar results about AKT may relate to the different stimuli and the experimental conditions. In our validation experiments, some results were not completely consistent on the two types of OSCC cell lines SCC-25 and CAL-27, for example, 

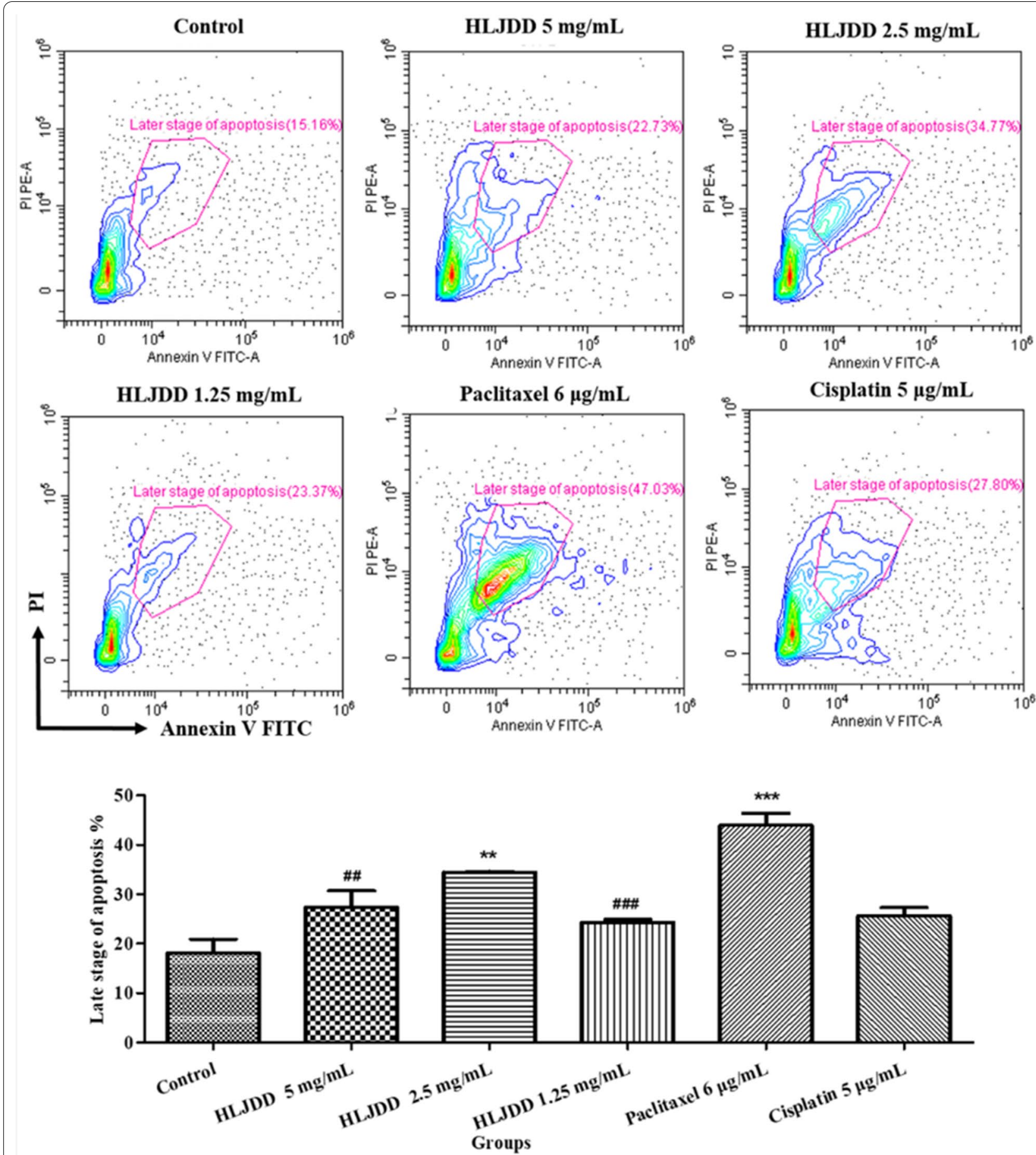

Fig. 5 The representative contour plots of six groups and the quantitative statistical chart. SCC- 25 cells were treated with HLJDD $5 \mathrm{mg} / \mathrm{mL}, \mathrm{HLJDD}$ $2.5 \mathrm{mg} / \mathrm{mL}$, HLJDD $1.25 \mathrm{mg} / \mathrm{mL}$, paclitaxel $6 \mu \mathrm{g} / \mathrm{mL}$ and cisplatin $5 \mu \mathrm{g} / \mathrm{mL}$ for $24 \mathrm{~h}$. Late stage of apoptosis determined by DxFLEX flow cytometry analyzer following Annexin V FITC and Propidium lodide (PI) staining. Both Annexin V FITC and PI positive cells represented that the cells were in

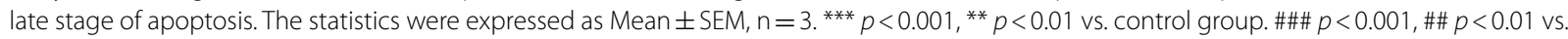
paclitaxel group. There were no significant differences between other groups and cisplatin group 


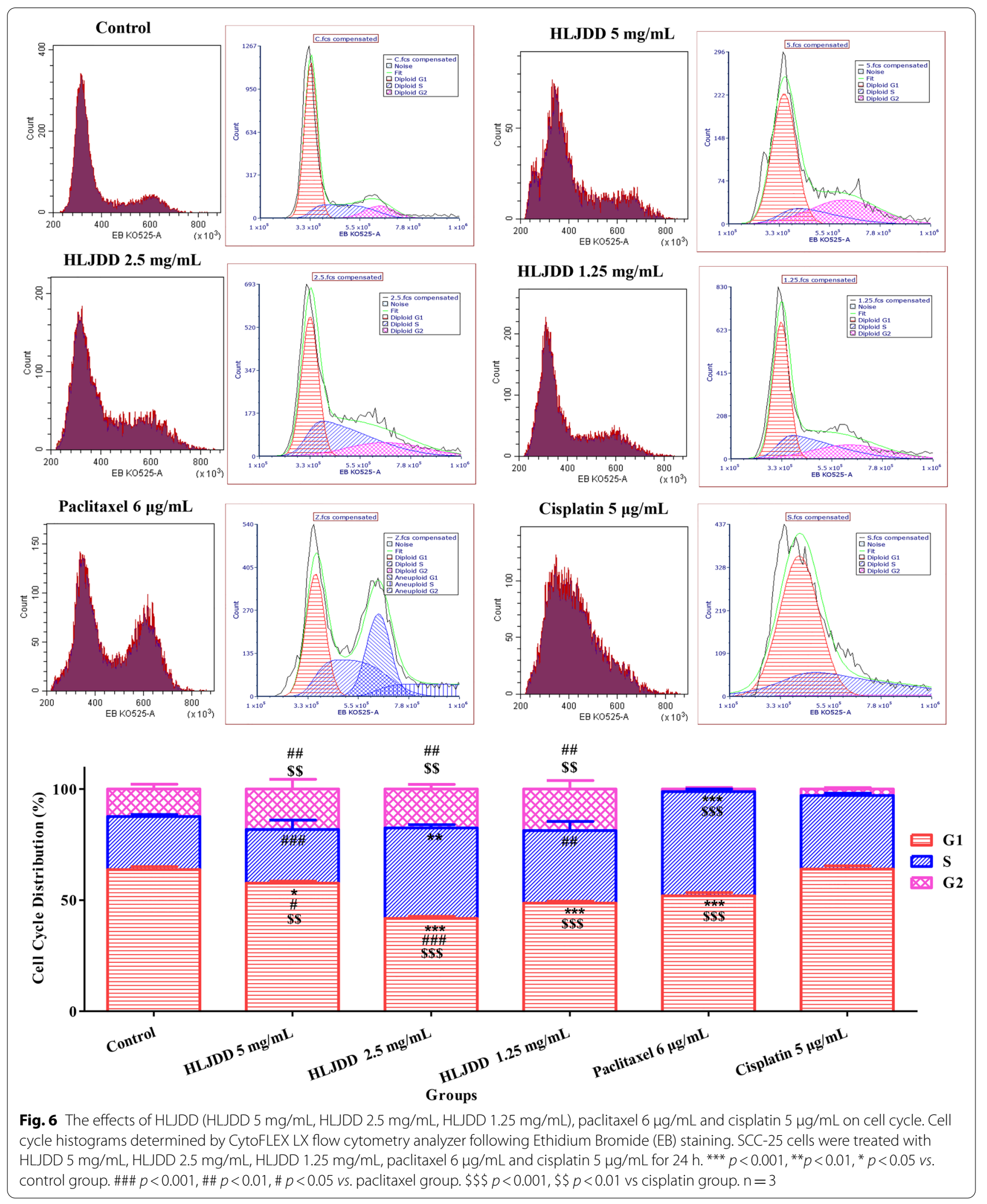




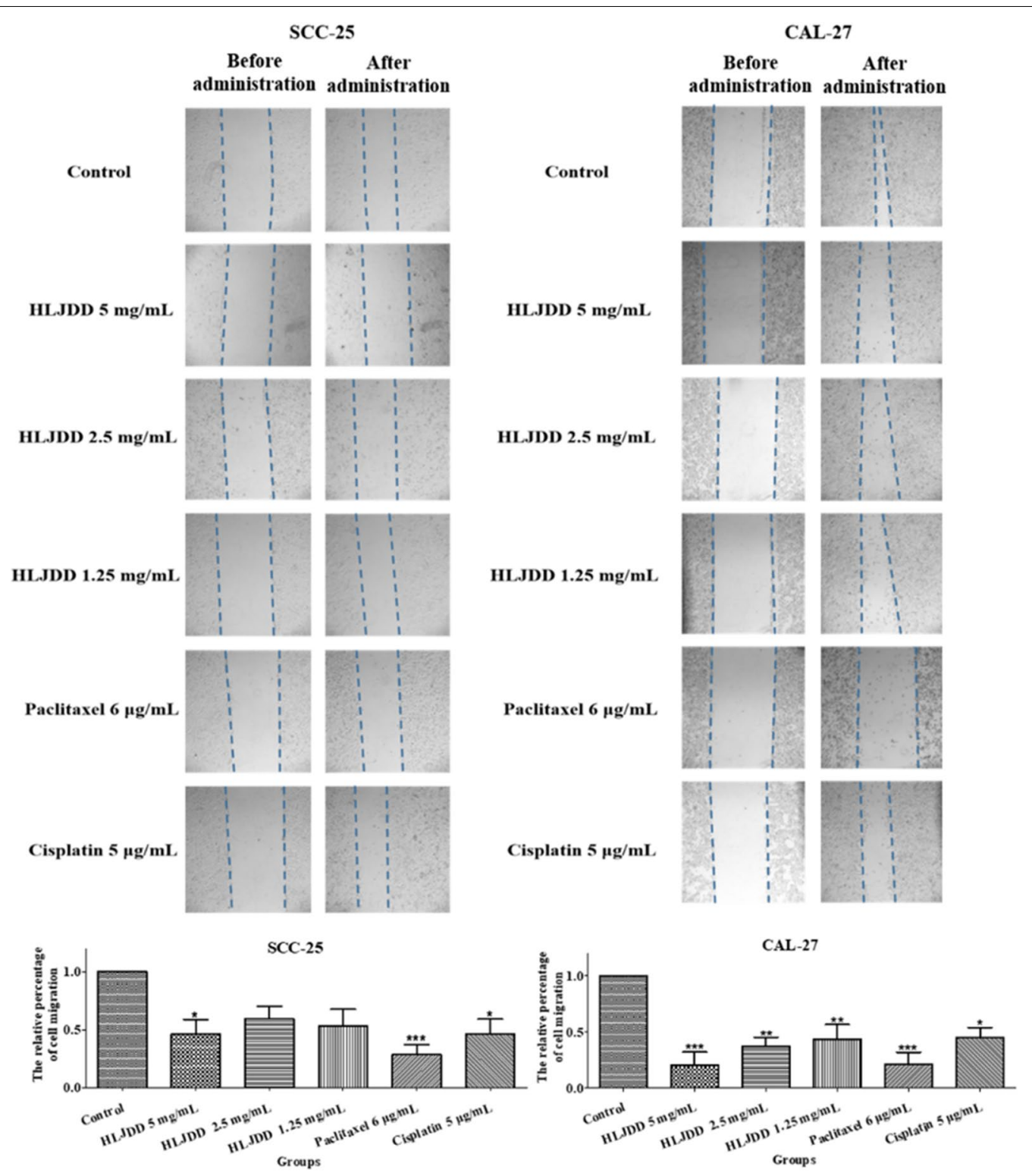

Fig. 7 The representative images of wound-healing assay in six groups. SCC-25 cells (left part) and CAL-27 cells (right part) were treated with HLJDD $5 \mathrm{mg} / \mathrm{mL}$, HLJDD $2.5 \mathrm{mg} / \mathrm{mL}$, HLJDD $1.25 \mathrm{mg} / \mathrm{mL}$, paclitaxel $6 \mu \mathrm{g} / \mathrm{mL}$ and cisplatin $5 \mu \mathrm{g} / \mathrm{mL}$ for $24 \mathrm{~h}$, respectively. All images both before administration and after administration were taken under microscope (original magnification, $\times 40$ ). The blue dotted line represented the area scratched by the $1000 \mu \mathrm{L}$-pipette tips. The statistics were expressed as Mean $\pm \mathrm{SEM}, \mathrm{n}=7$ (SCC-25 cells). ${ }^{*} p<0.05 \mathrm{vs}$. control group. The statistics were expressed as Mean \pm SEM, $n=4$ (CAL-27 cells). ${ }^{* *} p<0.001,{ }^{* *} p<0.01,{ }^{*} p<0.05$ vs. control group

paclitaxel significantly inhibited p-ERK1/2 in CAL-27, but not in SCC-25. We considered the possible reasons maybe different cell lines have different sensitivity for the drugs.

Surprisingly, after administration of HLJDD on SCC25 the expression of NF- $\mathrm{kB}$ p65 was reduced. We speculated that the synthesis of NF- $\mathrm{kB}$ p65 was decreased or degradation was increased. Sergej Skvortsov et al. found that CTFB, a novel anticancer drug, its anti-tumor activity was associated with down-regulation of NF- $\mathrm{kB}$ p 65 expression by activation of proteasome in $\mathrm{SCC}-25$ and CAL-27 cells [45]. Whether NF- $\kappa B$ p65 down regulation by HLJDD is related to proteasome activation or not needs further verification.

At first, we chose HLJDD (40 mg/mL, $20 \mathrm{mg} / \mathrm{mL}, 10$ $\mathrm{mg} / \mathrm{mL}, 5 \mathrm{mg} / \mathrm{mL}, 2.5 \mathrm{mg} / \mathrm{mL}$ and $1.25 \mathrm{mg} / \mathrm{mL}$ ), paclitaxel $(6 \mu \mathrm{g} / \mathrm{mL})$ and cisplatin $(5 \mu \mathrm{g} / \mathrm{mL})$ to stimulate CAL-27, we found that prolonging incubated time, the number of cells decreased visually. It indicated that 

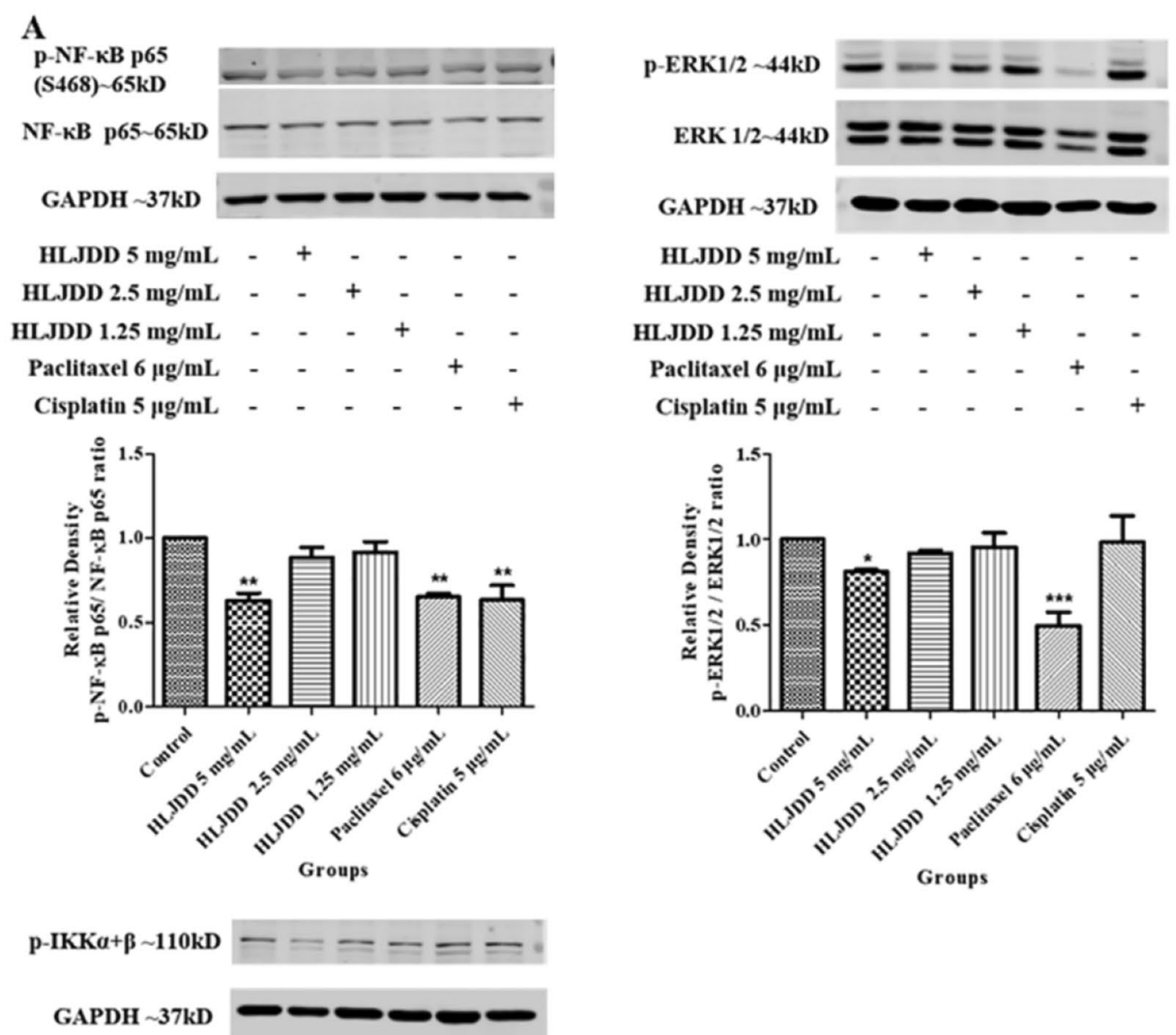

HLJDD $5 \mathrm{mg} / \mathrm{mL} \quad-\quad+\quad-\quad-$

HLJDD $2.5 \mathrm{mg} / \mathrm{mL} \quad-\quad+\quad+\quad-\quad-$

HLJDD $1.25 \mathrm{mg} / \mathrm{mL} \quad-\quad-\quad+\quad+\quad-$

Paclitaxel $6 \mu \mathrm{g} / \mathrm{mL} \quad-\quad-\quad-\quad-\quad+\quad-$

Cisplatin $5 \mu \mathrm{g} / \mathrm{mL} \quad-\quad-\quad \begin{array}{llllll} & - & - & - & +\end{array}$

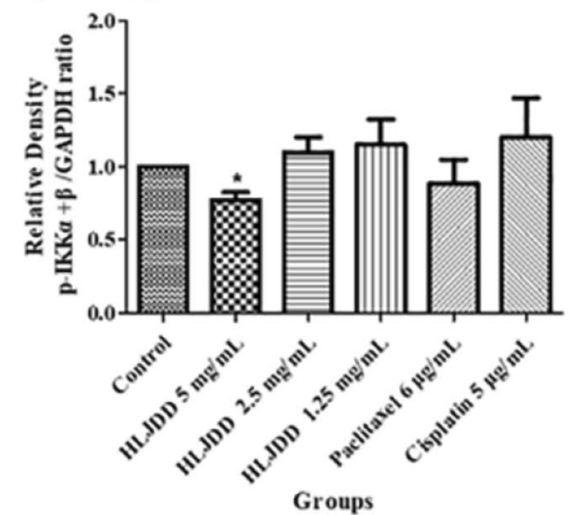

Fig. 8 HLJDD inhibited NF-KB and ERK pathway on CAL-27 and SCC-25. A CAL-27 cells were treated with HLJDD $5 \mathrm{mg} / \mathrm{mL}, \mathrm{HLJDD} 2.5 \mathrm{mg} / \mathrm{mL}$, HLJDD $1.25 \mathrm{mg} / \mathrm{mL}$, paclitaxel $6 \mu \mathrm{g} / \mathrm{mL}$ and cisplatin $5 \mu \mathrm{g} / \mathrm{mL}$ for $24 \mathrm{~h}$. We detected the expression of p-NF-KB p65 (S468), NF-KB p65, p-ERK1/2 and $p-I K K a+\beta$ by using the western blot analysis. The statistics were expressed as Mean \pm SEM, $n=3$. ${ }^{* * *} p<0.001,{ }^{* *} p<0.01$, ${ }^{*} p<0.05$ vs. control group. B SCC-25cells were treated with HLJDD $5 \mathrm{mg} / \mathrm{mL}$, HLJDD $2.5 \mathrm{mg} / \mathrm{mL}$, HLJDD $1.25 \mathrm{mg} / \mathrm{mL}$, paclitaxel $6 \mu \mathrm{g} / \mathrm{mL}$ and cisplatin $5 \mu \mathrm{g} / \mathrm{mL}$ for $24 \mathrm{~h}$. We detected the expression of p-NF-KB p65 (S468), NF-KB p65, p-ERK1/2 and p-IKK $a+\beta$ by using the western blot analysis. The statistics were expressed as Mean $\pm \mathrm{SEM}, \mathrm{n}=3 .{ }^{* * *} p<0.001,{ }^{* *} p<0.01,{ }^{*} p<0.05 \mathrm{vs}$. control group 


\section{B}

$$
\text { p-NF- } \kappa B \text { p } 65
$$

(S468) $65 \mathrm{kD}$

\section{GAPDH $\sim 37 \mathrm{kD}$}

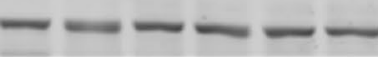

HLJDD $5 \mathrm{mg} / \mathrm{mL}$

HLJDD $2.5 \mathrm{mg} / \mathrm{mL}$

HLJDD $1.25 \mathrm{mg} / \mathrm{mL} \quad-\quad-\quad+\quad+\quad-$

Paclitaxel $6 \mu \mathrm{g} / \mathrm{mL} \quad-\quad-\quad-\quad-\quad+\quad-$

Cisplatin $5 \mu \mathrm{g} / \mathrm{mL}$

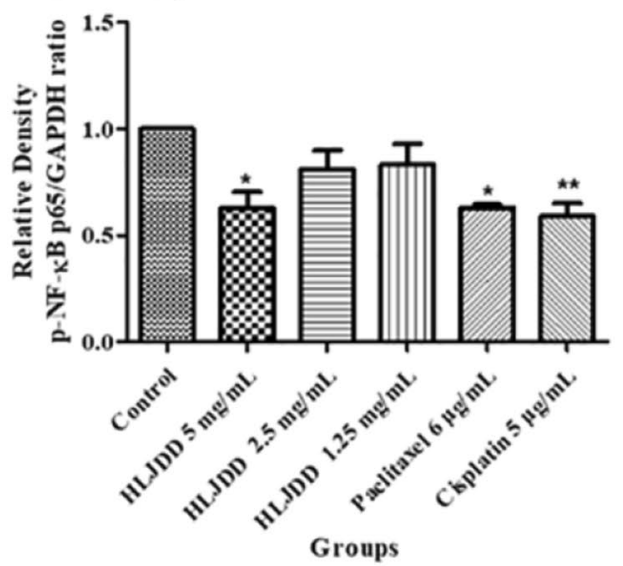

p-ERK1/2 -44kD $=\square=$

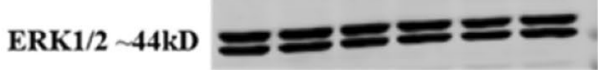

GAPDH 37kD $--\cdots$

HLJDD $5 \mathrm{mg} / \mathrm{mL} \quad-\quad+\quad-\quad-\quad-$

HLJDD $2.5 \mathrm{mg} / \mathrm{mL} \quad-\quad+\quad+\quad-\quad-$

HLJDD $1.25 \mathrm{mg} / \mathrm{mL} \quad-\quad-\quad-\quad+\quad-\quad-$

Paclitaxel $6 \mu \mathrm{g} / \mathrm{mL} \quad-\quad-\quad-\quad+\quad+\quad-$

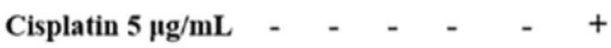

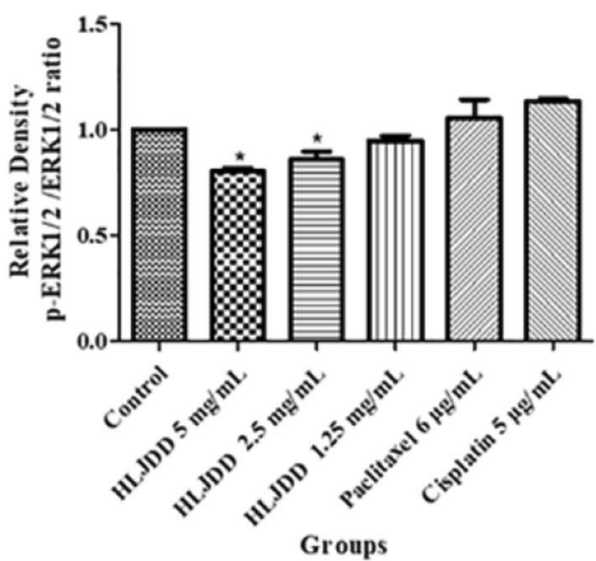

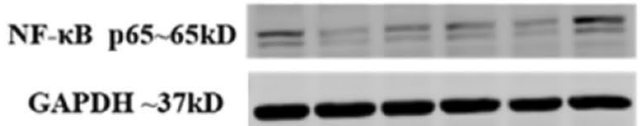

HLJDD $5 \mathrm{mg} / \mathrm{mL} \quad-\quad+\quad-\quad-\quad-$

HLJDD $2.5 \mathrm{mg} / \mathrm{mL} \quad-\quad-\quad+\quad-\quad-\quad-$

HLJDD $1.25 \mathrm{mg} / \mathrm{mL} \quad-\quad-\quad-\quad+\quad-\quad-$

Paclitaxel $6 \mu \mathrm{g} / \mathrm{mL} \quad-\quad-\quad-\quad-\quad+\quad-$

Cisplatin $5 \mu \mathrm{g} / \mathrm{mL} \quad-\quad-\quad-\quad-\quad-\quad+$
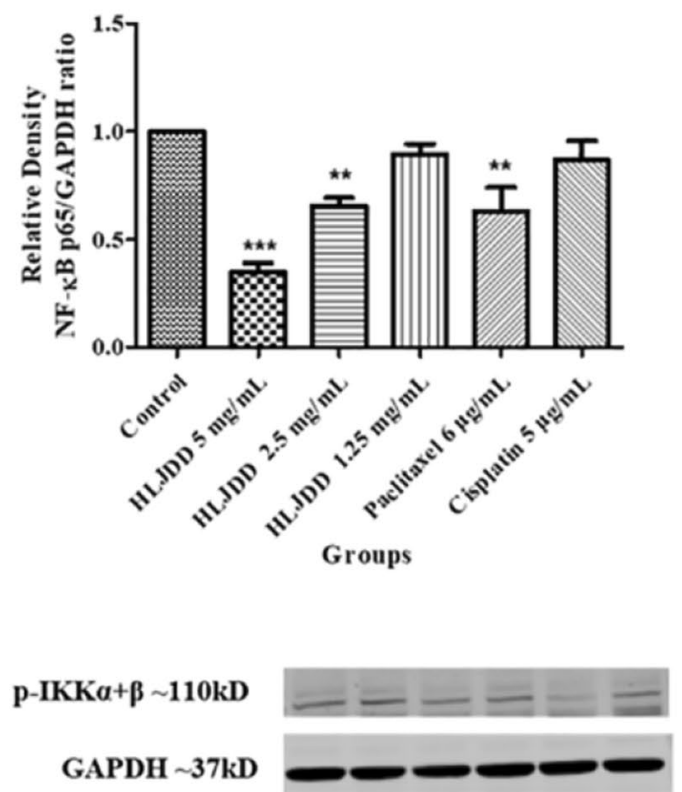

HLJDD 5 mg/mL - +

HLJDD $2.5 \mathrm{mg} / \mathrm{mL} \quad-\quad+\quad+\quad-\quad-$

HLJDD $1.25 \mathrm{mg} / \mathrm{mL} \quad-\quad-\quad-\quad+\quad-\quad-$

Paclitaxel $6 \mu \mathrm{g} / \mathrm{mL} \quad-\quad-\quad-\quad-\quad+\quad-$

Cisplatin $5 \mu \mathrm{g} / \mathrm{mL} \quad-\quad-\quad-\quad-\quad-\quad+$

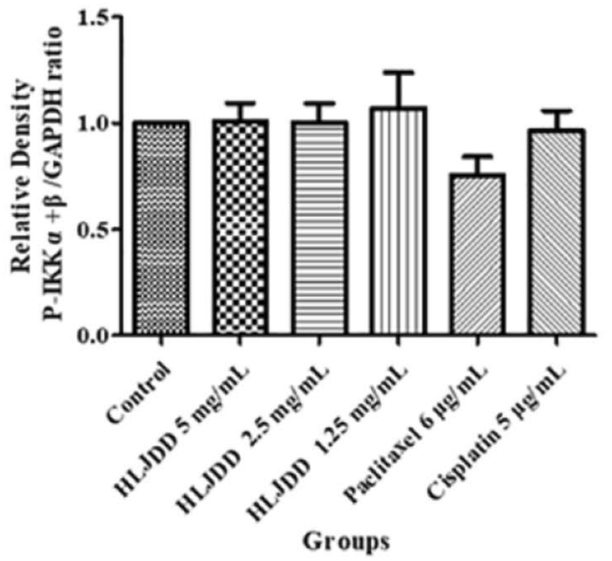

Fig. 8 continued 
HLJDD, paclitaxel and cisplatin inhibit cells proliferation (Additional file 2: Fig. S2). Combining with the CCK-8 results (Additional file 3: Fig. S3 A) and SRB results (Additional file 3: Fig. S3 B), it was obvious to see that the best time for cell harvesting was $24 \mathrm{~h}$ after administration, because the cell inhibitory rate was greater than $60-70 \%$ at $48 \mathrm{~h}$ or $72 \mathrm{~h}$ after administration. The SRB results showed that $5 \mathrm{mg} / \mathrm{mL}$ HLJDD group had higher inhibitory effect than that of $10 \mathrm{mg} / \mathrm{mL}$ HLJDD group after administration for $24 \mathrm{~h}$ (Additional file 3: Fig. S3 B). That's why we chose doses of $1.25 \mathrm{mg} / \mathrm{mL}, 2.5 \mathrm{mg} / \mathrm{mL}$, and $5 \mathrm{mg} / \mathrm{mL}$ HLJDD. However, HLJDD did not showed obvious dose-effect relationship. $5 \mathrm{mg} / \mathrm{mL}$ HLJDD showed stronger inhibition on cell migration (Fig. 7), and significantly reduced p-ERK1/2 and p-NF-KB p65 (S468) expression (Fig. 8), while $2.5 \mathrm{mg} / \mathrm{mL}$ HLJDD showed stronger suppression on cell cycle and apoptosis (Figs. 5 and 6). So, we speculated that $2.5 \mathrm{mg} / \mathrm{mL}$ HLJDD was a relatively sensitive concentration for cell cycle and apoptosis, while $5 \mathrm{mg} / \mathrm{mL}$ HLJDD may have stronger action on other biological processes of cell. Thus, in different evaluation indicators, different concentrations reflect different results. As for the observations on late stage apoptosis (Additional file 4: Fig. S4) and cell division cycle (Additional file 5: Fig. S5) on CAL-27, $1.25 \mathrm{mg} / \mathrm{mL}$ HLJDD significantly increased apoptosis in late stage, while 2.5 $\mathrm{mg} / \mathrm{mL}$ and $5 \mathrm{mg} / \mathrm{mL}$ HLJDD just slightly increased. The ability of $1.25 \mathrm{mg} / \mathrm{mL}$ HLJDD and $5 \mu \mathrm{g} / \mathrm{mL}$ cisplatin to induce late apoptosis on CAL-27 were similar, which were consistent with the results of SCC-25 (Fig. 5). But on CAL-27, the promoting effect of $2.5 \mathrm{mg} / \mathrm{mL}$ HLJDD on late apoptosis was not as obvious as that on SCC-25. Although the effects of the same dose of HLJDD were inconsistent on SCC-25 and CAL-27, all three doses of HLJDD can induce late stage apoptosis in SCC-25 and CAL-27. In Fig. S5, the percentage of cell in S phase in HLJDD $(5 \mathrm{mg} / \mathrm{mL}, 2.5 \mathrm{mg} / \mathrm{mL}, 1.25 \mathrm{mg} / \mathrm{mL})$ groups were $31.44 \%, 34.48 \%, 32.53 \%$, respectively, while that of control, paclitaxel $(6 \mu \mathrm{g} / \mathrm{mL})$ and cisplatin $(5 \mu \mathrm{g} / \mathrm{mL})$ groups were $24.40 \%, 24.10 \%$ and $57.19 \%$, respectively. HLJDD and cisplatin could elevate the percentages of cell in $\mathrm{S}$ phase, but only cisplatin group had a significant increase when compared with control group. In a word, HJLDD can promote late stage of cell apoptosis and increase the proportion of $\mathrm{S}$ phase in the cell cycle to inhibit the proliferation of SCC-25 and CAL-27 cell lines.

Based on our results, we found that not all enrichment analysis results were in line with experiments. It indicated that network pharmacology just provided some directions and specific targets needed further experimental verification.

\section{Conclusions}

Our study was the first time using the network pharmacology to explore the mechanism about HLJDD on OSCC. We screened 52 core targets by topological analysis. Based on GO-BP, GO-CC, GO-MF and KEGG pathway enrichment analysis, we found that 52 core targets were involved in biological processes such as cell cycle, apoptosis and activation of MAPK pathway. We further experimentally verified on OSCC cell lines (SCC-25 and CAL-27). The results supported that HLJDD inhibited cell proliferation on CAL-27 and SCC- 25 by promoting the late apoptosis of the cells, inhibiting the G1 phase (pre-DNA synthesis), arresting the $\mathrm{S}$ phase in the cell cycle on SCC-25 and inhibiting p-ERK1 / 2 and p-NF-kB p65 (S468) on SCC-25 and CAL-27. So HLJDD could be a potential drug for the treatment of OSCC.

\section{Abbreviations}

AKT: Protein kinase B; GO: Gene Ontology; HLDD: Huanglianjiedu Decoction; HPLC: High Performance Liquid Chromatography; KEGG: Kyoto Encyclopedia of Genes and Genomes; MAPK: Mitogen-activated protein kinase; MS: Mass spectrometry; NF-kB: Nuclear factor-kappa B; OMIM: Online Mendelian Inheritance in Man; OSCC: Oral squamous cell carcinoma; p-ERK1/2: Phosphateextracellular regulated protein kinases1/2; PPI: Protein-protein interaction; TCMSP: Traditional Chinese Medicine Systems Pharmacology Database and Analysis Platform; TTD: Therapeutic Target Database.

\section{Supplementary Information}

The online version contains supplementary material available at https://doi. org/10.1186/s12935-021-02201-6.

Additional file 1: Fig. S1. Study on mechanism of HLJDD on CAL-27, SCC-25 cell lines and quantitative graphs. (A) CAL-27 cells were treated with HLJDD 5 mg/mL, HLJDD $2.5 \mathrm{mg} / \mathrm{mL}$, HLJDD $1.25 \mathrm{mg} / \mathrm{mL}$, paclitaxel $6 \mu \mathrm{g} / \mathrm{mL}$ and cisplatin $5 \mu \mathrm{g} / \mathrm{mL}$ for 24 hours. We detected the expression of p-AKT, AKT, p-p38, p-NF-kB p65 (S529) and p-NF-KB p65 (S276) by using the western blot analysis. $n=2-3$. (B) SCC -25 cells were treated with HLJDD 5 mg/mL, HLJDD 2.5 mg/mL, HLJDD 1.25 mg/mL, paclitaxel $6 \mu \mathrm{g} /$ $\mathrm{mL}$ and cisplatin $5 \mu \mathrm{g} / \mathrm{mL}$ for 24 hours. We detected the expression of p-AKT, AKT, p-p38, p-JNK and p-NF-KB p65 (S276) by using the western blot analysis. $\mathrm{n}=2-3$.

Additional file 2: Fig. S2. Representative images of six groups (original magnification $200 \times$ ). CAL-27 cells were treated with HLJDD (40 mg/mL, $20 \mathrm{mg} / \mathrm{mL}, 10 \mathrm{mg} / \mathrm{mL}, 5 \mathrm{mg} / \mathrm{mL}, 2.5 \mathrm{mg} / \mathrm{mL}$ and $1.25 \mathrm{mg} / \mathrm{mL}$ ), paclitaxel 6 $\mu \mathrm{g} / \mathrm{mL}$ and cisplatin $5 \mu \mathrm{g} / \mathrm{mL}$.

Additional file 3: Fig. S3. The inhibitory effects of HLJDD, paclitaxel and cisplatin on CAL-27 cell line were detected by Sulforhodamine B (SRB) (KeyGEN BioTECH, Nanjing, China) and CCK-8 measurement (C0037, Beyotime Biotechnology., Shanghai, China) after administration for 24, 48 and $72 \mathrm{~h}$. $\mathrm{n}=6$. (A) CAL-27 cells were treated with HLJDD $(40 \mathrm{mg} / \mathrm{mL}, 20$ $\mathrm{mg} / \mathrm{mL}, 10 \mathrm{mg} / \mathrm{mL}, 5 \mathrm{mg} / \mathrm{mL}, 2.5 \mathrm{mg} / \mathrm{mL}$ and $1.25 \mathrm{mg} / \mathrm{mL}$ ), paclitaxel 6 $\mu \mathrm{g} / \mathrm{mL}$ and cisplatin $5 \mu \mathrm{g} / \mathrm{mL}$. After administration for 24,48 and $72 \mathrm{~h}$, we used CCK-8 measurement to analyze the inhibition effect of drugs on CAL 27 cell line. (B) CAL-27 cells were treated with HLJDD $(10 \mathrm{mg} / \mathrm{mL}, 5 \mathrm{mg}$ / $\mathrm{mL}, 2.5 \mathrm{mg} / \mathrm{mL}$ and $1.25 \mathrm{mg} / \mathrm{mL}$ ), paclitaxel $6 \mu \mathrm{g} / \mathrm{mL}$ and cisplatin $5 \mu \mathrm{g} /$ $\mathrm{mL}$. After administration for 24,48 and $72 \mathrm{~h}$, we used SRB measurement to analyze the inhibition effect of drugs on CAL-27 cell line.

Additional file 4: Fig. S4. The representative contour plots of six groups and the quantitative statistical chart. CAL-27 cells were treated with 
HLJDD 5 mg/mL, HLJDD 2.5 mg/mL, HLDD 1.25 mg/mL, paclitaxel $6 \mu \mathrm{g} /$ $\mathrm{mL}$ and cisplatin $5 \mu \mathrm{g} / \mathrm{mL}$ for $24 \mathrm{~h}$. Late stage of apoptosis determined by CytoFLEX S cytometry analyzer (Beckman Coulter, Inc. 250S. Kraemer Boulevard Brea, CA 92821, USA) following Annexin V APC and 7-AAD staining (abs50008, absin Bioscience Inc., Shanghai, China). Both Annexin $\checkmark A P C$ and 7-AAD positive cells represented that the cells were in late stage of apoptosis. The statistics were expressed as Mean $\pm S E M, n=3$. ${ }^{* * *} p<0.001,{ }^{* *} p<0.01$ vs. control group. \#\# $p<0.001$, \#\# $p<0.01$ vs. paclitaxel group. There were no significant differences between other groups and cisplatin group.

Additional file 5: Fig. S5. The effects of HLJDD $(5 \mathrm{mg} / \mathrm{mL}, 2.5 \mathrm{mg} / \mathrm{mL}$, $1.25 \mathrm{mg} / \mathrm{mL}$ ), paclitaxel $6 \mu \mathrm{g} / \mathrm{mL}$ and cisplatin $5 \mu \mathrm{g} / \mathrm{mL}$ on cell cycle of CAL-27 cell line. Cell cycle histograms determined by CytoFLEX S flow cytometry analyzer (Beckman Coulter, Inc. 250S. Kraemer Boulevard Brea, CA 92821, USA) following Propidium lodide (PI) staining measurement (C1052, Beyotime Biotechnology., Shanghai, China). CAL-27 cells were treated with HLDDD $5 \mathrm{mg} / \mathrm{mL}$, HLDDD $2.5 \mathrm{mg} / \mathrm{mL}$, HLJDD $1.25 \mathrm{mg} /$ $\mathrm{mL}$, paclitaxel $6 \mu \mathrm{g} / \mathrm{mL}$ and cisplatin $5 \mu \mathrm{g} / \mathrm{mL}$ for $24 \mathrm{~h}$. ${ }^{* * *} p<0.001 \mathrm{vs}$. control group. \#\#\# $p<0.001$ vs. paclitaxel group. $\$ \$ p<0.001, \$ p<0.01$ vs. cisplatin group, $\mathrm{n}=3$.

\section{Acknowledgements}

The author appreciated Ting Ge and Changxin Zhou in school of Pharmacy, Zhejiang University, for their help to prepare the extract of HLJDD.

\section{Authors' contributions}

LZ and ZL performed network pharmacologic analysis and the experiments, collected and analyzed the data. LZ wrote the manuscript. ZH, MG and XZ provided technical support and advices toward study. HT designed the study and revised the manuscript. All authors read and approved the final manuscript.

\section{Funding}

The study was supported by the National Natural Science Foundation of China (Grant No. 81570056 and 81602822) and the Natural Science Foundation of Zhejiang province, China (Grant No. LY18H310002 and LQ14H290002).

\section{Availability of data and materials}

The data sets used and/or analyzed during the current study are available from the corresponding author on reasonable request.

\section{Declarations}

Ethics approval and consent to participate Not applicable.

\section{Consent for publication}

All listed authors have participated in the study and approved the submitted manuscript.

\section{Competing interests}

There are no known conflicts of interest associated with this publication and the authors have declared that no competing interest exists.

\section{Author details}

${ }^{1}$ Central Laboratory, The Fourth Affiliated Hospital, Zhejiang University School of Medicine, Yiwu, Zhejiang, China. ${ }^{2}$ Department of Pharmacology, School of Basic Medical Sciences, Zhejiang University, Hangzhou, Zhejiang, China. ${ }^{3}$ Department of Pharmacy, The Fourth Affiliated Hospital, Zhejiang University School of Medicine, Yiwu, Zhejiang, China. ${ }^{4}$ Department of Biochemistry, University of Alberta, Edmonton, AB, Canada. ${ }^{5}$ Department of Clinical Laboratory, Tongde Hospital of Zhejiang Province, Hangzhou, Zhejiang, China.

Received: 19 May 2021 Accepted: 6 September 2021

Published online: 21 October 2021

\section{References}

1. Thomson PJ. Perspectives on oral squamous cell carcinoma preventionproliferation, position, progression and prediction. J Oral Pathol Med. 2018;47:803-7.

2. Da SSD, Ferlito A, Takes RP, Brakenhoff RH, Valentin MD, Woolgar JA, et al. Advances and applications of oral cancer basic research. Oral Oncol. 2011;47:783-91.

3. Wheeler SE, Shi H, Lin F, Dasari S, Bednash J, Thorne S, et al. Tumor associated fibroblasts enhance head and neck squamous cell carcinoma proliferation, invasion, and metastasis in preclinical models. Head Neck. 2015;36:385-92.

4. Yadav P. Recent advances in head and neck cancer reconstruction. Indian J Plast Surg. 2014;47:185-90.

5. Caponigro F, Milano A, Basile M, lonna F, laffaioli RV. Recent advances in head and neck cancer therapy: the role of new cytotoxic and moleculartargeted agents. Curr Opin Oncol. 2006;18:247-52.

6. Williams MD. Integration of biomarkers including molecular targeted therapies in head and neck cancer. Head Neck Pathol. 2010;4:62-9.

7. Andrew L. Hopkins. Network pharmacology. Nat Biotechnol. 2007;25:1110-1.

8. Hopkins AL. Network pharmacology: the next paradigm in drug discovery. Nat Chem Biol. 2008;4:682-90.

9. Chen Y, Dong J, Liu J, Xu W, Wei Z, Li Y, et al. Network pharmacologybased investigation of protective mechanism of Aster tataricus on lipopolysaccharide-induced acute lung injury. Int J Mol Sci. 2019;20:1-17.

10. Li T, Baochen Z, Yue Z, Cheng W, Yali W, Zongxi S, et al. Network Pharmacology-Based identification of pharmacological mechanism of SQFZ injection in combination with Docetaxel on lung cancer. Sci Rep. 2019;9:1-12.

11. Kulshrestha A, Suman S, Ranjan R. Network analysis reveals potential markers for pediatric adrenocortical carcinoma. Onco Targets Ther. 2016;9:4569-81.

12. Ma C, Xu T, Sun X, Zhang S, Liu S, Fan S, et al. Network pharmacology and bioinformatics approach reveals the therapeutic mechanism of action of baicalein in hepatocellular carcinoma. Evid Based Comp Altern Med. 2019;2019:1-15.

13. Li J, Lu C, Jiang M, Niu X, Guo H, Li L, et al. Traditional chinese medicinebased network pharmacology could lead to new multicompound drug discovery. Evid Based Comp Altern Med. 2012;2012:1-11.

14. Li S, Zhang B. Traditional Chinese medicine network pharmacology: theory, methodology and application. Chin J Nat Med. 2013;11:110-20. https://doi.org/10.1016/S1875-5364(13)60037-0.

15. Liu L, Jiang P, Dong SS, Liu RH, Zhang C, Zhang WD. Advances in studies on chemical constituents in Huanglian Jiedu Tang and their pharmacology. Chinese Tradit Herb Drugs. 2008;39:935-8 (in Chinese).

16. Zheng Y, Cheng XR, Zhou WX, Zhang YX. Gene expression patterns of hippocampus and cerebral cortex of senescence-accelerated mouse treated with Huang-Lian-Jie-Du decoction. Neurosci Lett. 2008;439:119-24

17. Ye Y, Huang C, Jiang L, Shen X, Zhu S, Rao Y, et al. Huanglian-Jie-Du-Tang extract protects against chronic brain injury after focal cerebral ischemia via hypoxia-inducible-factor-1a-regulated vascular endothelial growth factor signaling in mice. Biol Pharm Bull. 2012;35:355-61.

18. Ohta Y, Kobayashi T, Nishida K, Sasaki E, Ishiguro I. Preventive effect of Oren-gedoku-to (Huanglian-Jie-Du-Tang) extract on the development of stress-induced acute gastric mucosal lesions in rats. J Ethnopharmacol. 1999;67:377-84.

19. Xu Y, Guo S, Chen G, Zhang M, Zhang X, Dou D. Evaluation of anti-sepsis activity by compounds with high affinity to lipid a from HuanglianJiedu decoction. Immunopharmacol Immunotoxicol. 2017;39:364-70.

20. Chen Y, Xian Y, Lai Z, Loo S, Chan WY, Lin ZX. Anti-inflammatory and antiallergic effects and underlying mechanisms of Huang-Lian-Jie-Du extract: implication for atopic dermatitis treatment. J Ethnopharmacol Elsevier. 2016;185:41-52.

21. Sun J, Wen QH, Song Y, Li X, Jin J. Study on antitumor activities of Huanglian Jiedu decoction. China J Chinese Mater Medica. 2006;31:1461-3 (in Chinese). 
22. Wu XD, Wang YL. 30 cases of tongue cancer with Admixture of Huanglian Jiedu Decoction treatment. Shanxi Tradit Chinese Med. 2002;23:1078 (in Chinese).

23. Wang N, Feng Y, Tan HY, Cheung F, Hong M, Lao L, et al. Inhibition of eukaryotic elongation factor-2 confers to tumor suppression by a herbal formulation Huanglian-Jiedu decoction in human hepatocellular carcinoma. J Ethnopharmacol. 2015;164:309-18.

24. Ru J, Li P, Wang J, Zhou W, Li B, Huang C, et al. TCMSP: A database of systems pharmacology for drug discovery from herbal medicines. J Cheminform. 2014;6:1-6.

25. Li YH, Yu CY, Li XX, Zhang P, Tang J, Yang Q, et al. Therapeutic target database update 2018: enriched resource for facilitating bench-to-clinic research of targeted therapeutics. Nucleic Acids Res. 2018;46:D1121-7.

26. Bateman A, Martin MJ, O'Donovan C, Magrane M, Apweiler R, Alpi E, et al. UniProt: a hub for protein information. Nucleic Acids Res. 2015:43:D204-12

27. Amberger JS, Bocchini CA, Schiettecatte F, Scott AF, Hamosh A. OMIM. org: online Mendelian Inheritance in Man $\left(\mathrm{OMIM}^{\circledR}\right)$, an Online catalog of human genes and genetic disorders. Nucleic Acids Res. 2015;43:789-98.

28. Li L, Lei Q, Zhang S, Kong L, Qin B. Screening and identification of key biomarkers in hepatocellular carcinoma: evidence from bioinformatic analysis. Oncol Rep. 2017;38:2607-18.

29. Franceschini A, Szklarczyk D, Frankild S, Kuhn M, Simonovic M, Roth A, et al. STRING v9.1: protein-protein interaction networks, with increased coverage and integration. Nucleic Acids Res. 2013;41:808-15.

30. Huang DW, Sherman BT, Lempicki RA. Systematic and integrative analysis of large gene lists using DAVID bioinformatics resources. Nat Protoc. 2009;4:44-57.

31. Shannon P, Markiel A, Ozier O, Baliga NS, Wang JT, Ramage D, et al. Cytoscape: a software environment for integrated models. Genome Res. 1971;13:2498-504.

32. Martin A, Ochagavia ME, Rabasa LC, Miranda J, Fernandez-de-Cossio J, Bringas R. BisoGenet: a new tool for gene network building, visualization and analysis. BMC Bioinform. 2010;11:1-9. https://doi.org/10.1186/ 1471-2105-11-91.

33. Tang Y, Li M, Wang J, Pan Y, Wu FX. CytoNCA: a cytoscape plugin for centrality analysis and evaluation of protein interaction networks. BioSystems. 2015;127:67-72. https://doi.org/10.1016/j.biosystems.2014.11.005.

34. Bindea G, Mlecnik B, Hackl H, Charoentong P, Tosolini M, Kirilovsky A, et al. ClueGO: a Cytoscape plug-in to decipher functionally grouped gene ontology and pathway annotation networks. Bioinformatics. 2009:25:1091-3.

35. Durairajan SSK, Iyaswamy A, Shetty SG, Kammella AK, Malampati S, Shang $W$, et al. A modified formulation of Huanglian-Jie-Du-Tang reduces memory impairments and $\beta$-amyloid plaques in a triple transgenic mouse model of Alzheimer's disease. Sci Rep. 2017;7:1-13. https://doi. org/10.1038/s41598-017-06217-9.
36. Wang Z, Li C, Jiang M, Chen J, Yang M, Pu J. Filamin A (FLNA) regulates autophagy of bladder carcinoma cell and affects its proliferation, invasion and metastasis. Int Urol Nephrol. 2018;50:263-73. https://doi.org/10. 1007/s11255-017-1772-y.

37. Wang WT, Chen YH, Hsu JL, Leu WJ, Yu CC, Chan SH, et al. Terfenadine induces anti-proliferative and apoptotic activities in human hormonerefractory prostate cancer through histamine receptor-independent Mcl-1 cleavage and Bak up-regulation. Naunyn Schmiedebergs Arch Pharmacol. 2014;387:33-45.

38. Zuo R, Wang HJ, Si N, Zhao HY, Yang J, Bian BL. LC-FT-ICR-MS analysis of the prototypes and metabolites in rat plasma after administration of Huang-Lian-Jie-Du Decoction. Acta Pharm Sin. 2014;49:237-43 (in Chinese).

39. Li Z, Chen L, Xie R, Zhou X. Establishment of quality evaluation system of Huang 1 ian Jiedu decoction based on fingerprint technology and comprehensive scoring method. Guid J TCM. 2020;26:28-35 (in Chinese).

40. Zhang WN, Li AP, Qi YS, Qin XM, Li ZY. Metabolomics coupled with system pharmacology reveal the protective effect of total flavonoids of Astragali Radix against adriamycin-induced rat nephropathy model. J Pharm Biomed Anal. 2018;158:128-36. https://doi.org/10.1016/j.jpba.2018.05. 045.

41. Yue SJ, Xin LT, Fan YC, Li SJ, Tang YP, Duan JA, et al. Herb pair DangguiHonghua: mechanisms underlying blood stasis syndrome by system pharmacology approach. Sci Rep. 2017;7:1-15. https://doi.org/10.1038/ srep40318.

42. Wang S, Wang H, Lu Y. Tianfoshen oral liquid: a CFDA approved clinical traditional Chinese medicine, normalizes major cellular pathways disordered during colorectal carcinogenesis. Oncotarget. 2017;8:14549-69.

43. Wu K, Wei P, Liu M, Liang X, Su M. To reveal pharmacological targets and molecular mechanisms of curcumol against interstitial cystitis. J Adv Res. 2019:20:43-50.

44. Wu H, Li L, Ai Z, Yin J, Chen L. Pristimerin induces apoptosis of oral squamous cell carcinoma cells via $\mathrm{G} 1$ phase arrest and MAPK/ErK1/2 and AKt signaling inhibition. Oncol Lett. 2019;17:3017-25.

45. Tsov S, Skvortsova I, Stasyk T, Schiefermeier N, Neher A, Gunkel AR, et al. Antitumor activity of CTFB, a novel anticancer agent, is associated with the down-regulation of nuclear factor-kB expression and proteasome activation in head and neck squamous carcinoma cell lines. Mol Cancer Ther. 2007;6:1898-908.

\section{Publisher's Note}

Springer Nature remains neutral with regard to jurisdictional claims in published maps and institutional affiliations.

Ready to submit your research? Choose BMC and benefit from:

- fast, convenient online submission

- thorough peer review by experienced researchers in your field

- rapid publication on acceptance

- support for research data, including large and complex data types

- gold Open Access which fosters wider collaboration and increased citations

- maximum visibility for your research: over $100 \mathrm{M}$ website views per year

At BMC, research is always in progress.

Learn more biomedcentral.com/submissions 